\title{
Wedge and Conical Probes for the Instantaneous Measurement of Free-Stream Flow Quantities at Supersonic Speeds
}

\author{
Percy J. Bobbitt ${ }^{1}$ and Domenic J. Maglieri ${ }^{2}$ \\ Eagle Aeronautics, Inc., Hampton, Virginia, 23669 \\ Daniel W. Banks ${ }^{3}$ \\ NASA, Dryden Flight Research Center, Edwards, California, 93523 \\ Aaron W. Fuchs 4 \\ Jacobs, Technology, NASA Langley Research Center, Hampton, VA 23681
}

\begin{abstract}
Wedge and conical shaped probes for the measurement of free-stream flow quantities at supersonic speeds have been tested in both wind tunnel and flight. These probes have improved capabilities over similar ones used in the past. Through the use of miniature pressure sensors, that are located inside the probes, they are able to provide instantaneous measurements of a time-varying environment. Detailed herein are the results of the tests in NASA Langley Researcher Center's Unitary Plan Wind Tunnel (UPWT) at Mach numbers of 1.6, 1.8 and 2.0, as well as flight tests carried out at the NASA Dryden Flight Research Center (DFRC) on its F-15 aircraft up to Mach numbers of 1.9. In the flight tests the probes were attached to a fixture on the underside of the F-15 fuselage. Problems controlling the velocity of the flow through the conical probe, required for accurate temperature measurements, are noted, as well as some calibration problems of the miniature pressure sensors that impact the accuracy of the measurements.
\end{abstract}

\section{Introduction}

The capability to accurately measure Mach number, pressure and angle-of-attack at supersonic speeds is important for wind tunnel and flight research as well as flight operations. In flight research, it can be used to define the instantaneous in-flight conditions of a generating or probing aircraft, as well as to make diagnostic measurements in the generating aircraft's flow-field. It is also important in avoiding focussed booms by aiding in the control of the ascent and descent, and the associated acceleration, of supersonic capable aircraft.

Changes in altitude and attitude and the resultant changes in freestream pressure and temperature, along with changes in velocity all contribute to Mach number variations. The conical and wedge probes, described herein, enable one to acquire these quantities instantaneously. They can also be used to make diagnostic measurements in the flow field of models. These data are useful for input into sonic boom propagation programs and for comparisons of flow field calculations

1. Vice President, 13 W. Mercury Blvd., Hampton, VA 23669, AIAA Fellow

2. Director for Projects, 13 W. Mercury Blvd., Hampton, VA 23669, AIAA Associate Fellow

3. Senior Aerospace Engineer, PO Box 273, Mail Stop 228, Edwards, AFB, CA 95523, Sr. Member AIAA

4. Test Engineer, UPWT, 600 William Northern Blvd., Tullahoma, TN 37188, not an AIAA member 
by Euler and Navier-Stokes CFD codes. The determination of these quantities is made possible, in part, by taking advantage of the exact Euler-equations, analyses of conical flow carried out as far back as 1933 (refs. 1-7); and the wedge probe to those in references 3, 4, and 7.

There have been wedge and conical probes developed and used before, but the ones described herein have additional capability or utility. The conical probe, for example, makes a temperature measurement which allows it to determine, in addition to the above mentioned quantities, freestream static and total temperature, speed of sound, velocity and acceleration. The wedge probe utilized in the present investigation was similar to the one designed and fabricated in 1992 and described in reference 8. It has about twice the width of the 1992 version, i.e., about one-inch, which permits it to make measurements down to Mach numbers of $\sim 1.35$. Successful wind tunnel tests of the "original" wedge probe have already been made (ref. 8), however, the wedge probe has never been flight-tested.

Wind tunnel tests of the two probes were made in NASA Langley Research Center's Unitary Plan Wind Tunnel (UPWT) at Mach numbers of 1.6, 1.8 and 2.0 in the summer of 2010. In these wind tunnel tests, a 2-degree semi-angle cone probe, normally used for flow field diagnostics, was also tested and its data compared to that of the wedge probe. In addition, a bump was installed on the tunnel wall to create a shock system across the test section. The probes were translated through this flow field to simulate the types of measurements they are often required to make.

Flight tests were conducted at NASA Dryden Flight Research Center in March and April of 2011. They were carried out with the probes attached to a fixture on the underside of the fuselage of a NASA F-15 aircraft. Data from both the wind tunnel and flight tests will be presented, and described later in this paper.

\section{Background}

The use of probes to measure various free stream flow quantities is as old as flight itself. Pitot tubes for the measurement of pressures that, in turn, yield flow velocity are the most common and well known. Diagnostic probes specifically tailored for supersonic measurements probably got started in the late 1930's when the capability to produce supersonic flows using blow-down tunnels originated. Reference 9, published in 1949, details a number of devices for measuring pressure, Mach number and density. Included is the use of wedges, in different arrangements, to measure flow angle, pressure and Mach number. Figure 1, from reference 9, shows the arrangement of pressure taps on both sides of a wedge which enables flow angle calculations using the appropriate equations.

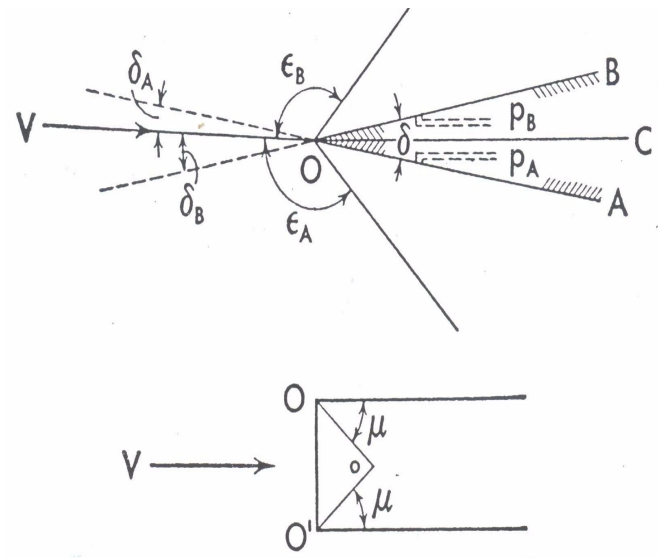

Figure 1. Instrument for the measurement of the flow direction (from ref. 9). 
A different and more capable wedge probe was used at the NASA Lewis Research Center (now John Glenn Research Center) and documented in reference 10. It has two free-stream total measurements behind the leading-edge shock and two static pressure taps (see fig. 2). The wedge angle is $20^{\circ}$ and it is 6-inches in width. With its size, it evidently was used for free-stream measurements rather than detailed diagnostics. Also due to the wedge angle of $20^{\circ}$, it must have been limited to Mach numbers above 1.84

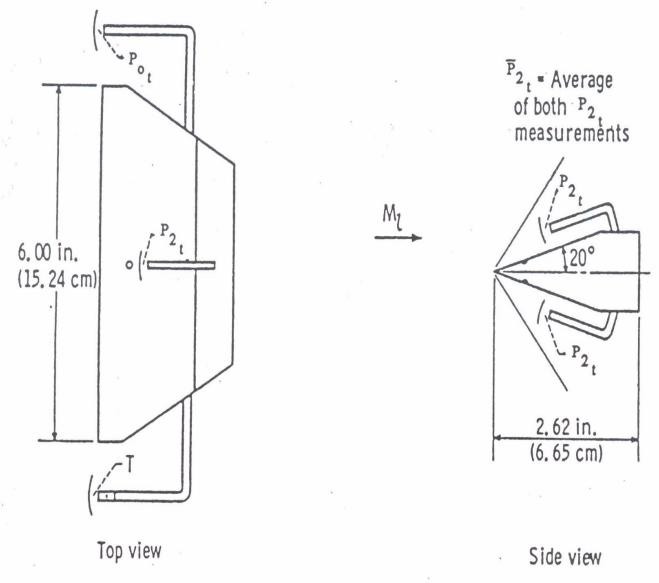

Figure 2. Details of large wedge probe design (from ref. 10)

The wedge probe described in the Introduction (see ref. 8) and shown in figure 3, is much smaller, six-tenths inch in width, and all of the three pressure measurements are made within 0.3 inch of the leading edge enabling very high resolution. The mathematics used, along with these measurements determine the free-stream flow quantities, is exact based on the Euler equations (see Appendix A).
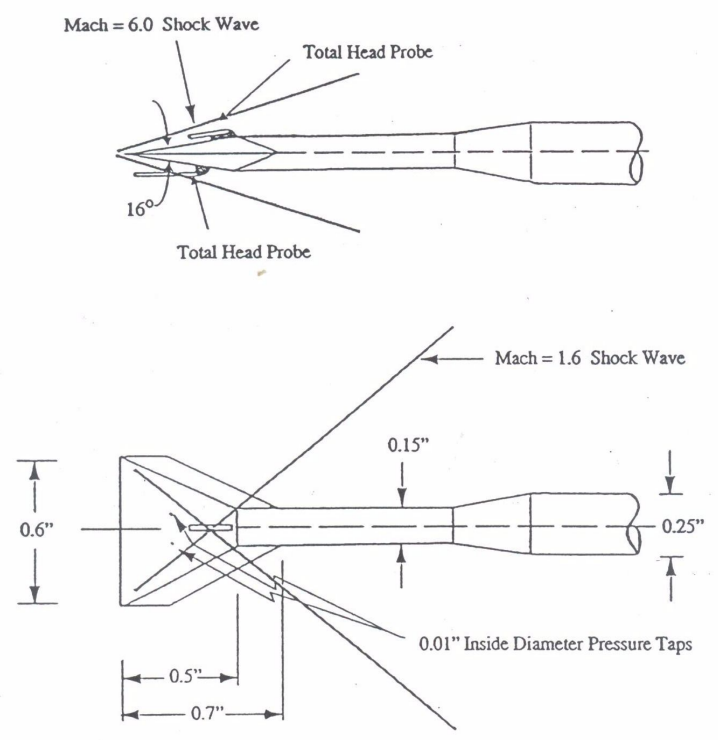

Figure 3. Wedge probe showing relationship of corner and leading-edge shocks to pressure sensors (from ref. 8). 
Reference 11 by Gorlin and Slezinger is a compilation of information concerning wind tunnels and their instrumentation. It discusses wedge, conical and pyramid probes but most are single purpose devices that measure Mach number (see sketch below) or flow direction or density, etc. It is a valuable resource because of its scope (592 pages) and other relevant papers that it references, such as reference 12 .

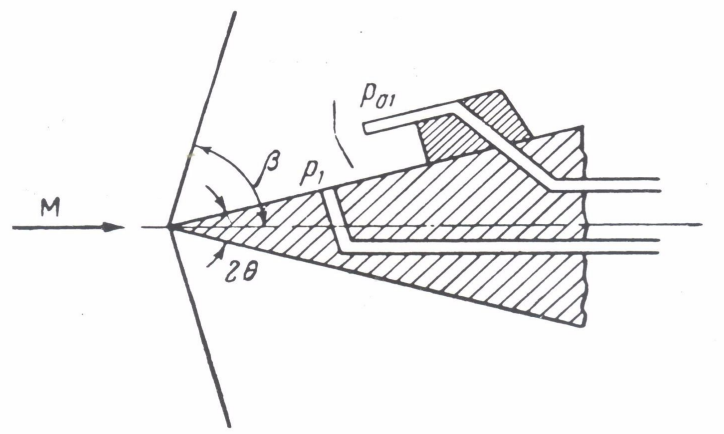

Wedge-shaped obstacle for measur-

ing Mach number.

Conical probes with a half-apex angle of $15^{\circ}$ have been used by NASA researchers in several flow-diagnostic research projects and documented in references 13 and 14. The geometry of the probe used in reference 13 is shown in figure 4 . With a diameter of $3 / 16$ th of an inch, the pressure orifices on the cone forebody are all within 0.2 inch of each other and the resolution is outstanding. The equations used to determine Mach number and flow angle from the measured pressures on the forebody $\left(15^{\circ}\right.$ cone $)$ are given in the paper and repeated in Appendix B. They were also used in the present investigation.

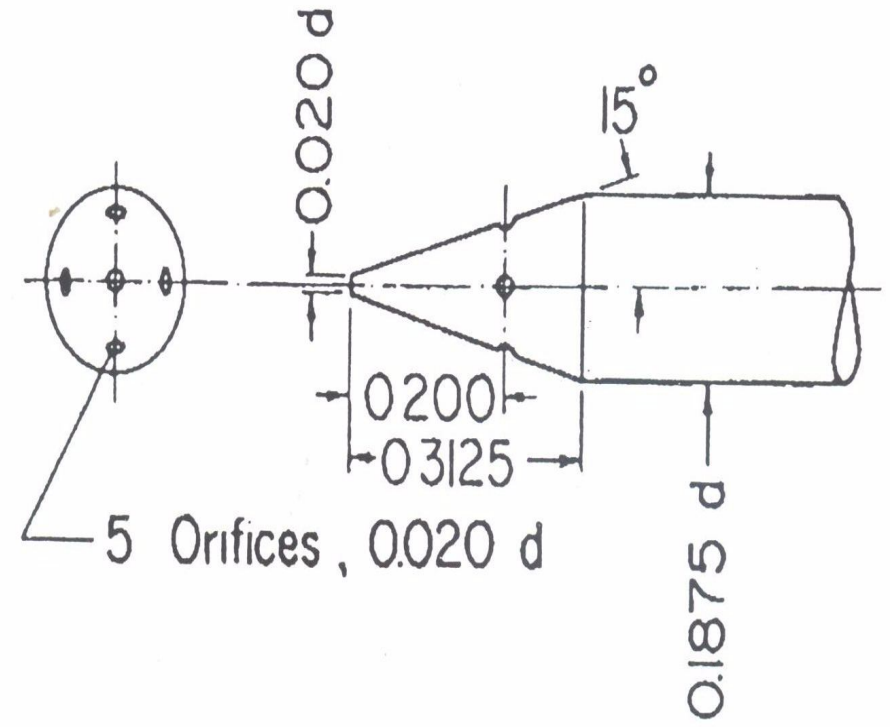

Figure 4. Detail of conical probe (from ref. 13). 
The cone geometry of the probe used in reference 14 is shown in figure 5 with its diameter of 0.189 inch $(0.48 \mathrm{~cm})$. Thus, it was essentially the same size as that of reference 13 and had the same resolution.

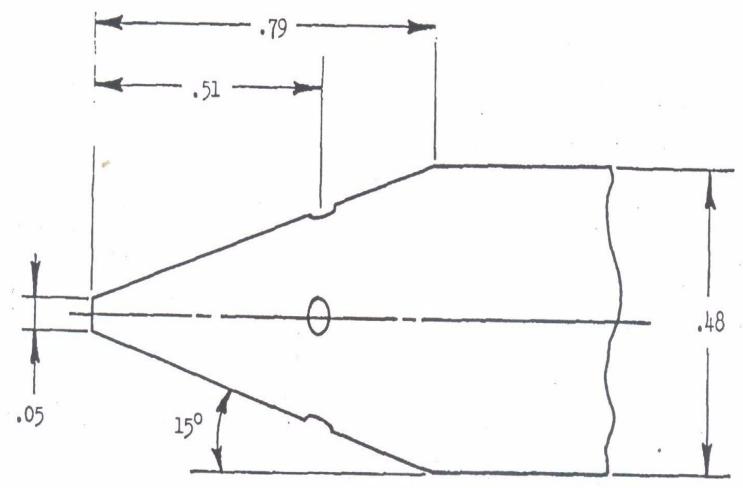

Figure 5. Sketch of conical probe. All dimensions are in centimeters unless otherwise noted (from ref. 14).

As noted earlier, a $2^{\circ}$ semi-apex angle cone was also used in the present investigation. It has been the "probe of choice" for wind-tunnel pressure measurements since the late 1970's. Due to the location of the static pressure ports and the length of the probe (see fig. 6) there are some intrinsic error sources.

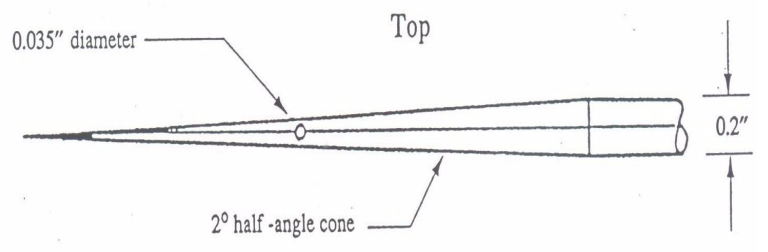

\section{Side}

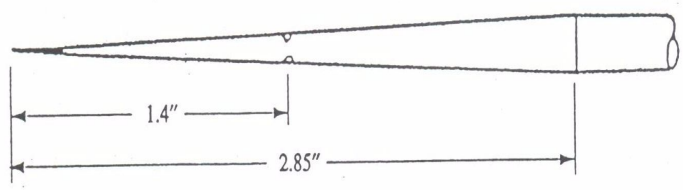

Figure 6. Geometry of conical pressure probe with $2^{0}$ half-angle. Pressure orifices on top and bottom.

In most of the tests using the $2^{\circ}$ semi-apex angle, cone probe, a second $2^{\circ}$ cone probe was used, as seen in the sketch below, to measure the static pressure in the free stream (see refs. 15 through 18). This measurement was then subtracted from that of the probe in the disturbed flow field to yield a more accurate measurement of the incremental pressure provided by the test model. It should be noted, however, that this increment is also "processed" by the shock system of the $2^{\circ}$ cone. 


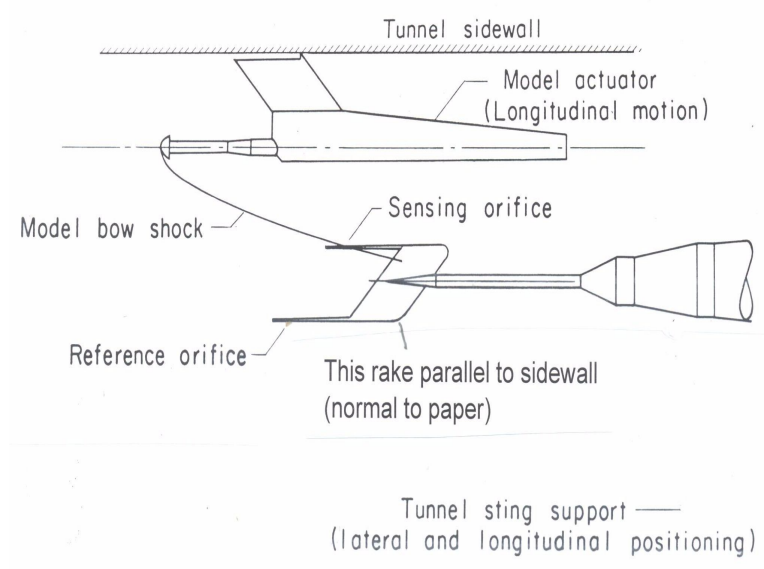

Sketch showing sidewall mounted model and rake with pressure probes.

Another error occurs when flow-field shocks intersect the cone in the vicinity of the pressure taps. If the probe has four taps and they are aligned vertically, and the probe is below the model, the bottom tap will see the shock before those on the side or top. To reduce this error, some experimenters have aligned the pressure taps with the expected incoming shock (see refs. 17 and 19).

In 1977 and 1978, papers by Carlson and Mack (refs. 18, 20) and Mack and Darden (ref. 21) reported using a $2^{\circ}$ semi-angle cone probe with pressure taps on the top and bottom as in figure 6 . However, it was oriented with the line through the two pressure taps normal to the plane of the model and the probe. Thus, the two pressure taps sensed the incoming shocks at the same time. This was an important characteristic, particularly for small models, in the selection of the $1^{\mathrm{O}}$ and $2^{\mathrm{O}}$ semi-angle cones in the early days of sonic boom experimentation.

There is also a very thin boundary layer on the cone which, when it interacts with the shock, allows the pressure orifices to feel the shock pressure rise before it actually reaches the orifices as well as after the shock has gone beyond the orifices. Figure 7, from reference 22, shows the shock-smearing produced by the probe for a $60^{\circ}$ delta wing. This wing had a 0.5 inch chord and was at $10^{\circ}$ angle-of-attack. Clearly, the larger the length of the model relative to the length of the probe, the less effect the smearing will have. Note that there is even more smearing on the boundary layer by-pass plate measurement which is all due to shock boundary-layer interaction. See reference 8 for additional discussion of the shock smearing phenomena. It should be noted that prior to 1960 that the boundary-layer bypass plate was the preferred instrument for measuring flow-field pressure (see ref. 23). 

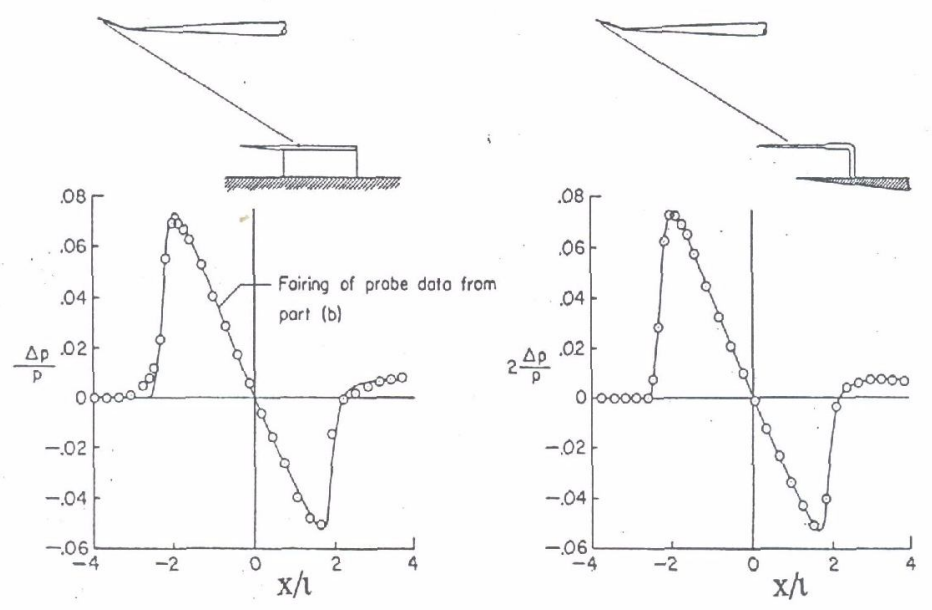

Figure 7. Comparison of pressure measurements made with a reflection plate and with a probe (from ref. 15) $60^{\circ}$ delta wing; $\alpha=10^{\circ} ; \mathrm{h} / l-16 ; \mathrm{M}=2.01$

\section{Description of New Wedge and Conical Probes}

The wedge probe used in the current measurements is twice as wide then that of reference 8 (see fig. 8) in order to allow measurements down to a Mach number of 1.35. With this width it keeps The shock from the corners of the wedge from passing in front of the static ports on the surface in the middle of the wedge. The probe of reference 8 was configured for Mach numbers of 1.6 and above.

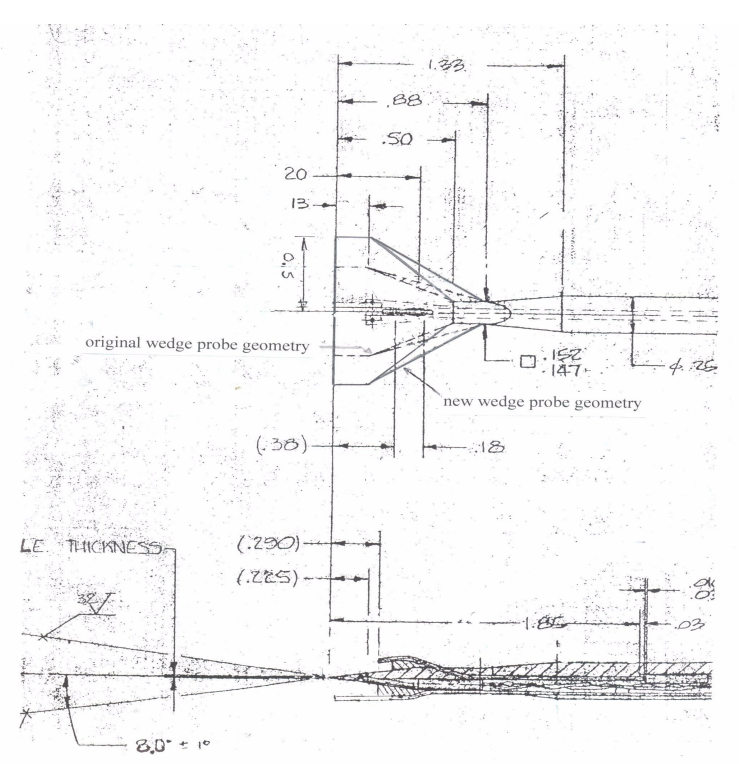

Figure 8. Details of wedge probe design.

The pressure measurements are made using cryogenic ultra miniature Kulite gages that are said to be capable of accurate measurements from $-320^{\circ} \mathrm{F}$ to $250^{\circ} \mathrm{F}\left(-195.5^{\circ} \mathrm{C}\right.$ to $\left.120^{\circ} \mathrm{C}\right)$. Three Kulites were installed in the wedge probe; one to measure static pressure and two that measure total pressure. These are absolute pressure gages of 5 psia and 10 psia, respectively. They are lin- 
ear up to two times rated pressure with no change in calibration and the bursting pressure is three times rated pressure. The gages are located in the holder just downstream of the wedge itself. Thus, there is essentially no time delay from the actual sensing of pressure at the orifices to the sensing by the Kulites. This is a great advantage in recording a transient event such as the varying pressures measured by one supersonic aircraft penetrating the flow field of another.

If one is only interested in the measurement of Mach number, freestream pressure and angleof-attack, there is a fairly simple and accurate way to do this based on conical flow methodology. As noted earlier, probes of this type have already been used successfully for wind tunnel flowfield surveys (refs. 13 and 14). They make use of exact cone theory and off-the-shelf pressure sensors and can be developed for several cone angles if desired. However, the best overall probe would probably have a semi-vertex angle between $15^{\circ}$ and $24^{\circ}$. This would enable Mach number measurements down to 1.12 (in the case of the $15^{\circ}$ semivertex cone angle) and up to hypersonic speeds. Only one total and four static pressure sensors are required. These gages can be located in the "holder" so that the measurements are instantaneous. Mach number is determined from an equation that relates Mach number to the average of the static cone pressures, the total pressure behind the nose shock and the magnitude of the flow angle determined. Overall diameter of the probe can be as small as $1 / 4$ inch.

The conical probe used in this investigation is similar to that shown in the schematic of figure 9 which is the version used for flight tests. In addition, it utilizes the same type Kulite pressure gages used in the wedge probe and it includes a temperature sensor, as well as one additional pressure sensor, for use in the correction of the temperature measured to the free-stream stagnation temperature. This additional pressure sensor (and associated orifice) was located in the channel just ahead of the temperature probe. Using these additional measurements of free-stream density, temperature, speed of sound, and velocity may be determined in addition to pressure, Mach number and flow angle. Measurements made using the conical probe are used in the equations of Appendix B to determine free-stream quantities. With the inclusion of the temperature sensor and the fact that the conical probe was to be used primarily for flight measurements, the diameter was set at 0.75 inch. Thus, in the wind tunnel measurements, shock jumps and steep gradients are smeared more than those for the 3/16 inch diameter conical probes described earlier.

The conical probe tested in the 4-foot Unitary Plan Wind tunnel had its total-pressure orifice in a cup inside the conical forebody of the probe. This was done to facilitate flow through the gage from the apex orifice. Obviously, to make the temperature measurement in a changing environment there must be flow through the gage. However, data for the response of the temperature sensor to a changing environment is available only for water. Thus, the amount of flow through the gage to measure a changing external temperature was just a guess. The guess was 15 to $20 \mathrm{ft} / \mathrm{sec}$ which is about 3 or 4 times the rate in water. It was thought, based on area and mass flow considerations, that with an 0.06 inch diameter apex hole and four 1/8 inch vent holes at the back end would yield the required velocity. 

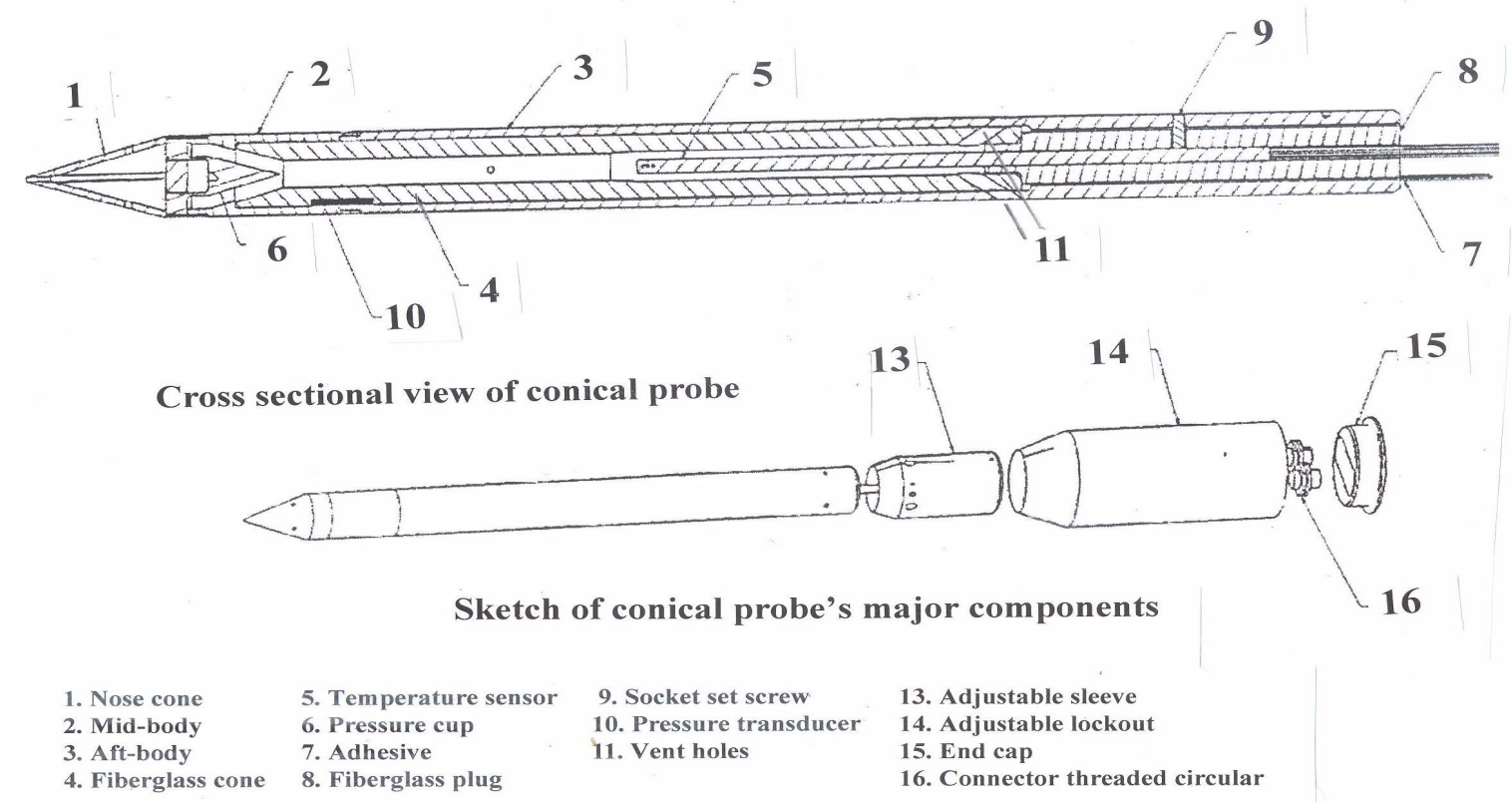

Figure 9. Details of conical probe design.

Preliminary tests in the Unitary Plan Wind Tunnel (UPWT) did not shed much light on the flow rate through the conical probe since the back-end was not totally sealed and the flow through the inside of the cone was clearly much larger than desired. Subsequently, in the tests reported on herein, additional leaks were found and eventually sealed to lend added concern about the "flowthrough" problem.

It became clear that during the tunnel tests that total pressure in the cup did not give an accurate measurement based on the total pressure measurements made by the wedge probe. In many cases the total pressure measured in the cup was smaller then the static pressure measured in the channel. It was also clear that one reason for this problem was our inability to achieve a flow velocity ahead of the cup as low as $15 \mathrm{ft} / \mathrm{sec}$ by varying the vent hole sizes in the back end. Velocities of this magnitude, or lower, enable the stagnation and the channel pressure to be within 0.1 percent or less of each other, and the measured stagnation pressure will be trivially different from the exact stagnation value. As a result of the wind tunnel tests, it was decided to move the total pressure orifice to the apex of the cone, as seen in the figure. Thus, there is an annulus around the total pressure tube at the apex of the cone as seen in the sketch of figure 10a and the photograph of figure 10b. The apex hole will be twice the diameter of the total pressure tube and four 1/32-inch vent holes at the back allow flow through the probe. This vent hole sizing was based on tests made during the wind tunnel tests. With this arrangement the total pressure measurement will be accurate and the temperature sensor, with the higher flow-through velocity, will be able to respond more quickly to changes in free-stream temperature than the original design. 


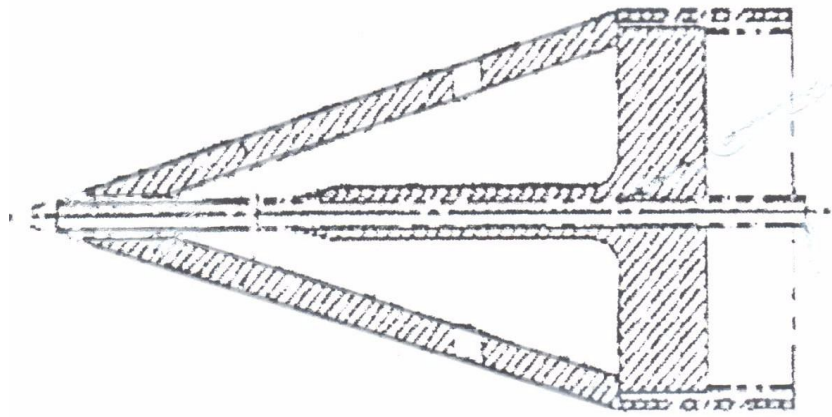

(a) Sketch of cross-sectionof cone.

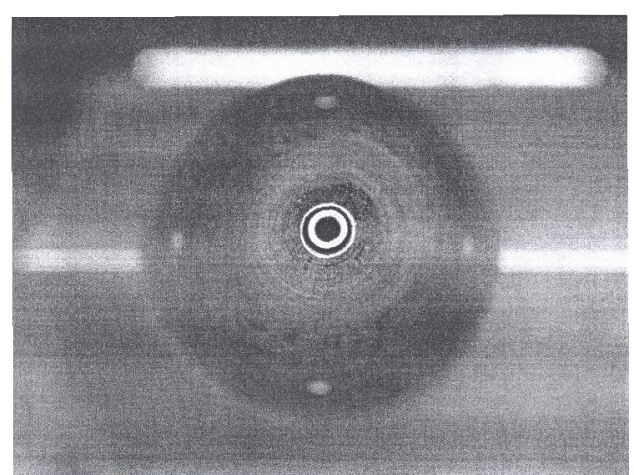

(b) Photograph of apex of cone.

Figure 10. Sketch and photograph showing total pressure tube at apex of cone and annulus around it.

Finally, due to the problems with the total pressure measured in the cup, the stagnation pressure measured by the wedge probe was used for the wind tunnel data reduction for the conical probe.

\section{Shock Generator}

In order to determine the ability of the probes to measure transient, non-uniform flows, a side wall disturbance bump was installed. This disturbance bump has the geometry shown in figure 11 and produces a bow shock of $\sim 0.21 \mathrm{psi}$. It has a circular arc surface geometry, a chord of 5 inches and a maximum thickness of 0.5 inch. Before the second tunnel entry a "secondary shock" bump was added in hopes of a generating a shock of about one-tenth that of the main shock. Its geometry is shown by the shaded area in figure 11. However, the boundary layer on the test section wall is about 4-inches thick and the disturbance caused by the secondary bump was smeared out. It did, however, cause a steeper pressure recovery, as expected.

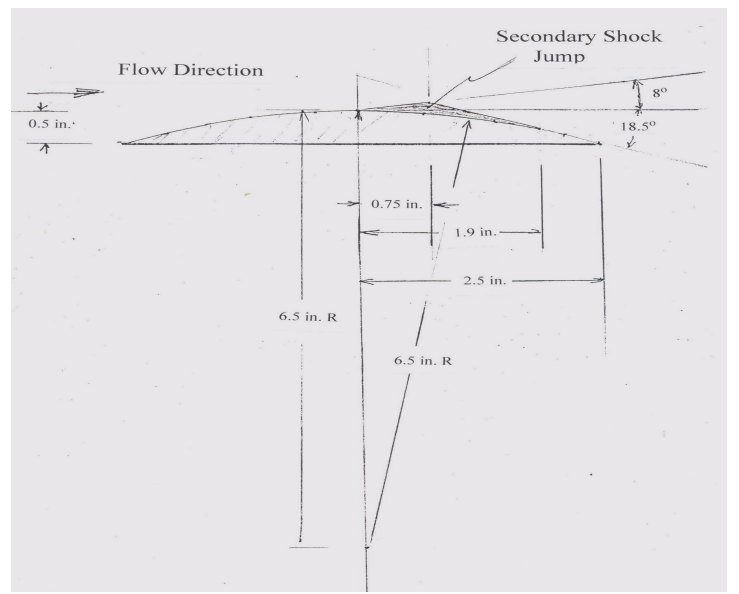

Figure 11. Sketch of tunnel wall disturbance bump design.

\section{Wind Tunnel Probe Holder}

A "probe holder" was designed that held the three probes such that the shocks off the apex of each probe did not interfere with an adjacent probe. A photograph of the probe holder with the probes installed is shown in figure 12. A view of the holder in the vertical position, along with the disturbance bump on the sidewall, is presented in figure 13. 


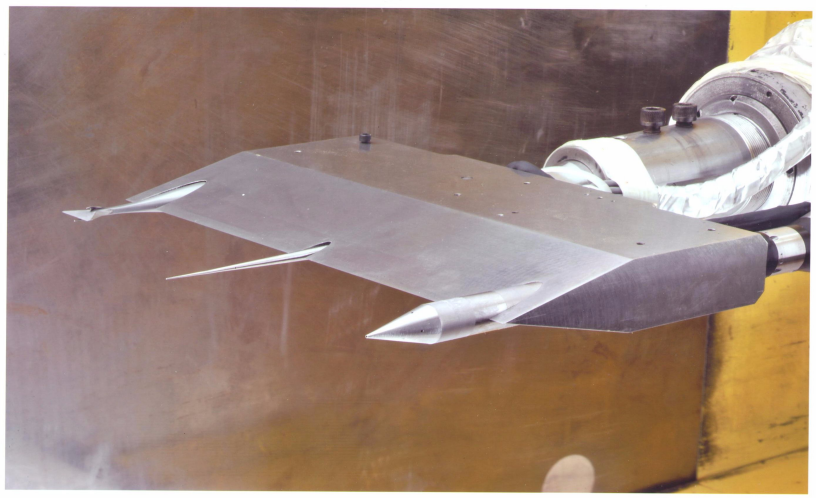

Figure 12. Photograph of three-probe sting arrangement in UPWT.

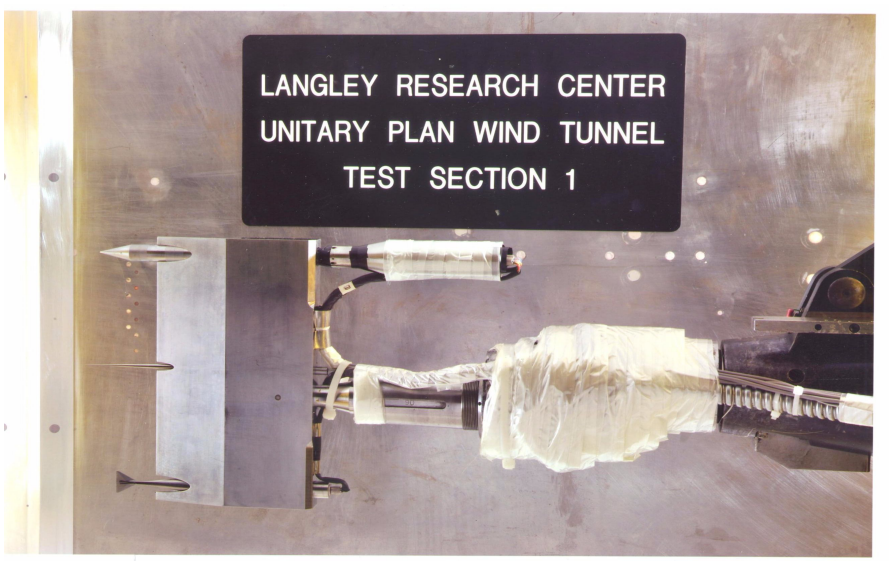

Figure 13. Photograph of probe alignment for wall disturbance bump shocks in UPWT.

The chord of the probe holder was limited by the fact that vent holes on the back end of the conical probe could not be blocked. Several of these holes can be seen just downstream of the trailing edge of the holder in figure 13. The apex of the various probes are not lined up so that each probe senses the bow-shock off the shock generator (wall disturbance bump) at a different time as the probes were moved longitudinally through its flow field.

\section{Flight Tests}

Flight tests of the probes were made at NASA Dryden Flight Research Center during the months of March and April 2011. The probes were installed on the bottom side of a so-called Centerline Instrumented Pylon or CLIP attachment (see fig. 14) installed on NASA's F-15. Figures 14a and 14b, taken from the air shows the entire airplane and a close-up of the CLIP installation, respectively. Figure 14c gives a better idea of the location of the probes relative to the leading edge of the CLIP. The longitudinal location of the front ends of the probes are not the same with the wedge probe being forward of the conical by $~ 1.0$ inch (see fig. 15).

At supersonic flight conditions, the shock off the leading edge of the CLIP is in close proximity to the sensor heads and with the wedge's more forward location it will be closest to the shock. Consequently as Mach number increases the shock off the sides of the CLIP and will pass over the wedge probe first. Conversely, as Mach number decreases the shock will pass back over the wedge probe after it has passed over the conical probe. Small changes in the location of the shock 
with respect to the sensors can result in changes larger than those seen in the free stream quantities due to the flow gradients (longitudinal and laterally) behind the U-shaped shock.

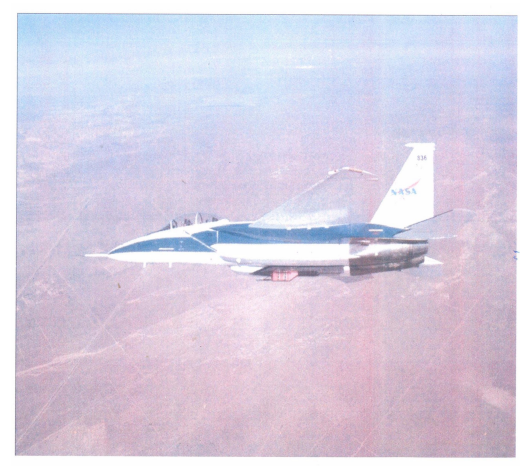

(a) Dryden F-15B with probes attached to CLIP.

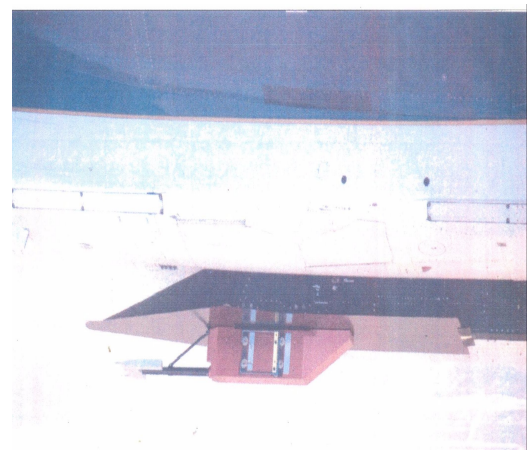

(b) Close-up of probe clip mounted under F-15B.

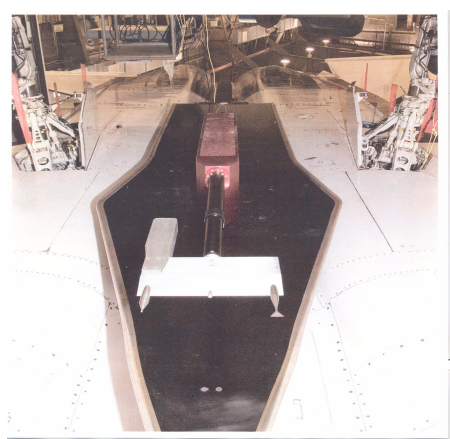

(c) Close-up of probe installation and CLIP.

Figure 14. Various photographs showing probe installation on NASA F-15 aircraft.

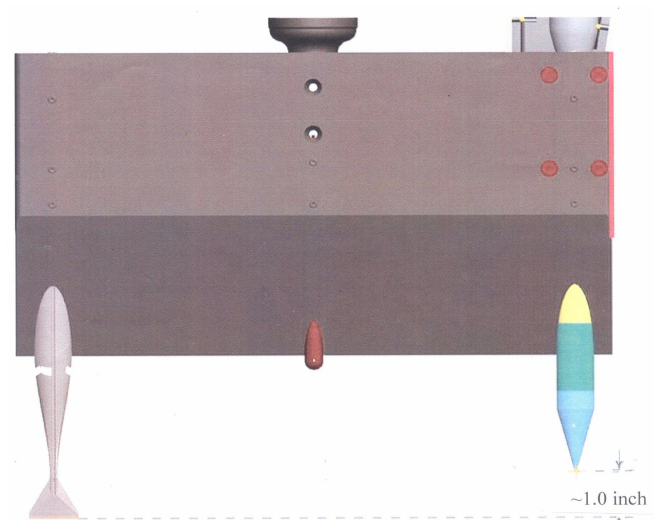

Figure 15. Sketch showing the difference in longitudinal location of wedge and conical probes.

\section{Results}

In this section, measurements of the free-stream flow variables are presented for both the wind tunnel and flight tests. In the case of the former, the transient longitudinal pressures due to the shock generator are also discussed. These quantities are determined from the measured pressures and the data reduction equations in Appendices A and B.

The pressures are measured using cryogenic Kulite gages with ranges of 5 and 10 psi depending on whether static or total pressures are being measured, respectively. They are said, by Kulite, to be temperature compensated down to a temperature of $-320^{\circ} \mathrm{F}$. The gages have a diameter of 0.066 inch and a length of 0.375 inch. The Kulite pressure gages with the $15^{\circ}$ conical and wedge probes were calibrated in a pressure chamber prior to, and following, the wind tunnel tests. In addition, a series of pressure calibrations were performed in the wind-tunnel during the no-flow pump-down phase which ranged from atmospheric pressures to slightly below $3.0 \mathrm{psi}$, and the results correlated with the pressure chamber calibration.

In flight, where the temperatures at 45 to 50 thousand feet may be as low as -75 or $-80^{\circ} \mathrm{F}$, accurate measurements require the temperature compensation capabilities that the Kulite gages are said to possess. Figure 16 shows calibrations, carried out at DFRC, for two 5 psi gages over tem- 
peratures from $-50^{\circ} \mathrm{F}$ to $+140^{\circ} \mathrm{F}$. The calibration for the 5 psi gages used for the upper pressure port (fig. 16a) on the cone shows a difference of $\sim 3$ percent between the $70^{\circ} \mathrm{F}$ calibration and the $50^{\circ} \mathrm{F}$ calibration at 5 psi pressure. The calibration of the gages used for the lower pressure port of the cone, shown in figure $16 \mathrm{~b}$, shows that the temperature is well compensated for over the range where calibration were made. The other gages used for the cone and the wedge show similar variations in temperature compensations. Later in this section, the affect the variances have on the determination of several of the free stream flow variables will be illustrated.

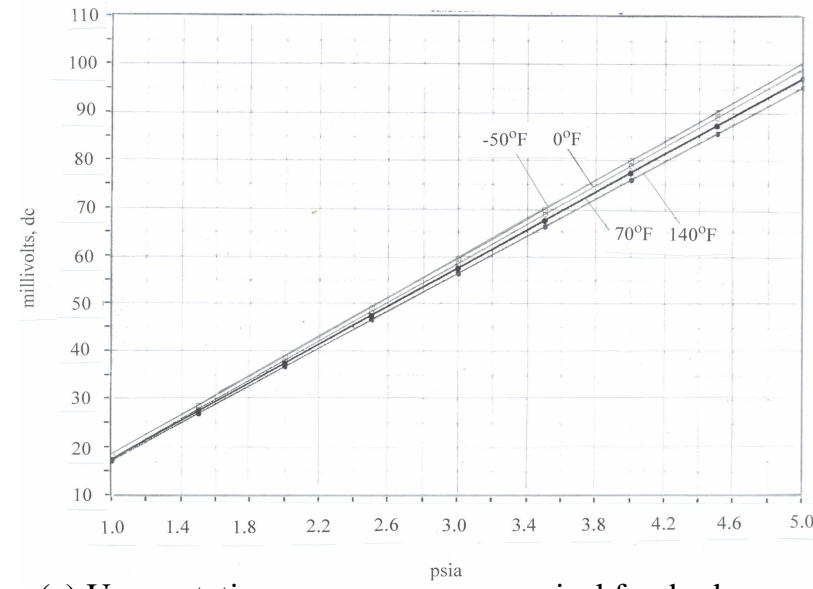

(a) Upper static pressure gage on conical forebody.

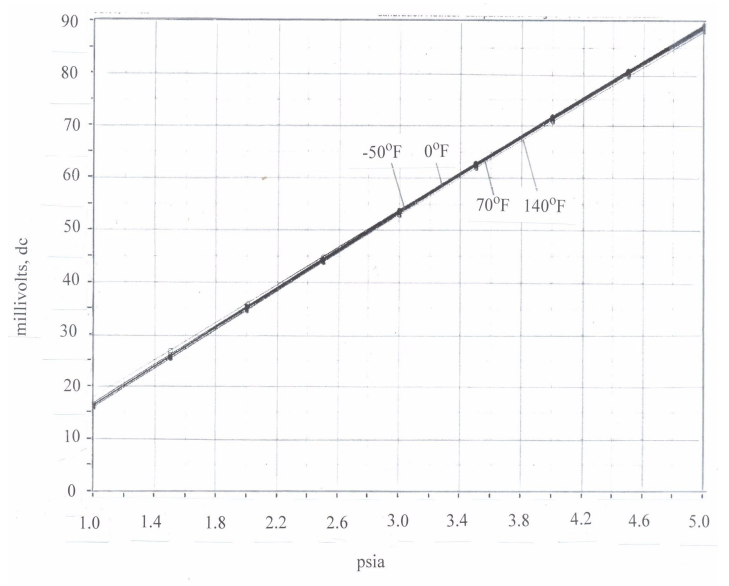

(b) Left-side static pressure gage on conical forebody.

Figure 16. Calibration of two conical probe gages at four temperatures from $-50^{\circ} \mathrm{F}$ to $140^{\circ} \mathrm{F}$.

\section{A. Wind Tunnel Flow Angle Measurements:}

Measurements were made at three nominal Mach numbers, 1.6, 1.8 and 2.0. The angles of attack were varied from $-8^{\circ}$ to $+8^{\circ}$. Data for these three Mach numbers are plotted in figure 17 . Figure 17a for a nominal Mach number of 1.6 shows that the measurements of both probes are linear with angle of attack. The wedge measurements agree quite well with the tunnel measurements but the conical values are higher by $\sim 0.5^{\circ}$.

(a) $\mathrm{M}=1.6$

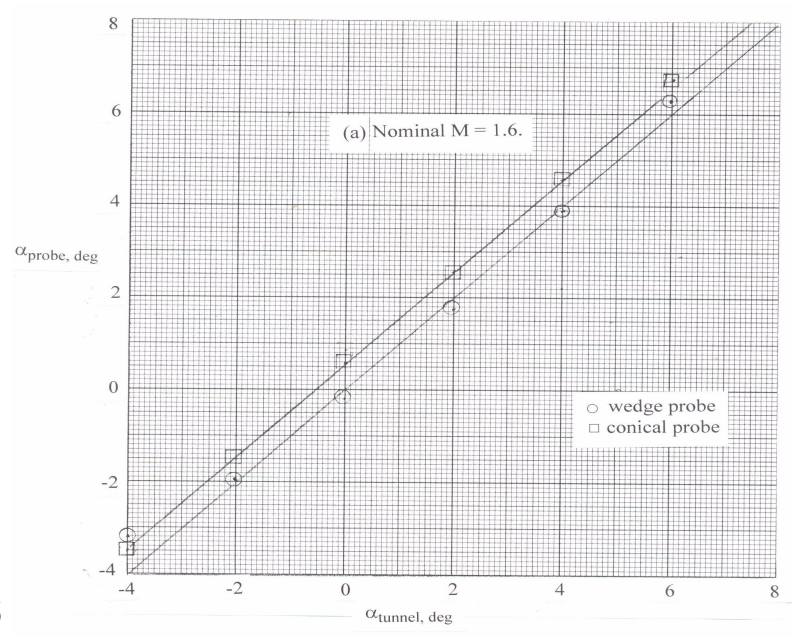

Figure 17. Comparison of probe measured flow angle to wind-tunnel angle-of-attack setting for three Mach numbers. 
For a nominal Mach number of 1.8 (fig. 17b) the wedge and the tunnel data agree but the conical data is about $0.8^{\circ}$ higher. Both sets of data are linear with angle-of-attack as for $\mathrm{M}=1.6$.

(b) $\mathrm{M}=1.8$

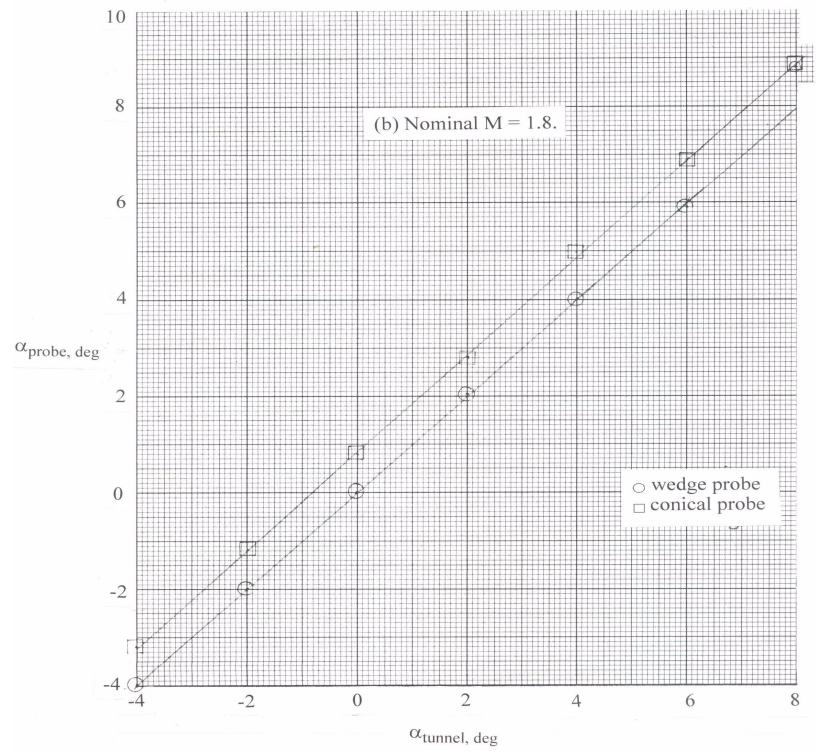

Figure 17. Continued.

For the nominal Mach 2.0 plot, figure 17c, neither sets of data agree with the tunnel angle-ofattack measurement. However, tunnel flow quality data at a Mach number of 2.0 indicate that there is clearly a flow angle at both the wedge and conical probes of $\sim 0.5^{\circ}$, which then moves both the wedge and conical data further from the tunnel data. Also, it appears that the conical probe is misaligned about $0.8^{\circ}$ with the wedge probe, thus, if the cone data are translated down $0.8^{\circ}$ in figures 17 , then the flow angle data would make more sense.

(c) $\mathrm{M}=2.0$

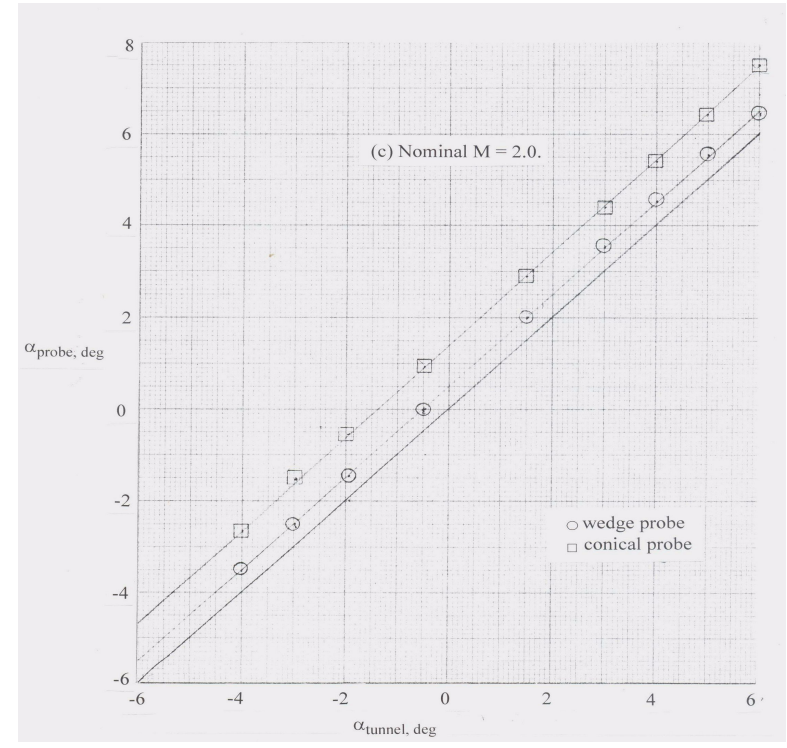

Figure 17. Concluded. 


\section{B. Wind Tunnel Static Pressure Measurements:}

The data of most interest is the pressure data since it is this quantity that is used in boom propagation codes. Figure 18 shows the static pressure data for the three nominal Mach numbers for the wedge and conical probes as well as the $2^{\mathrm{O}}$ cone.

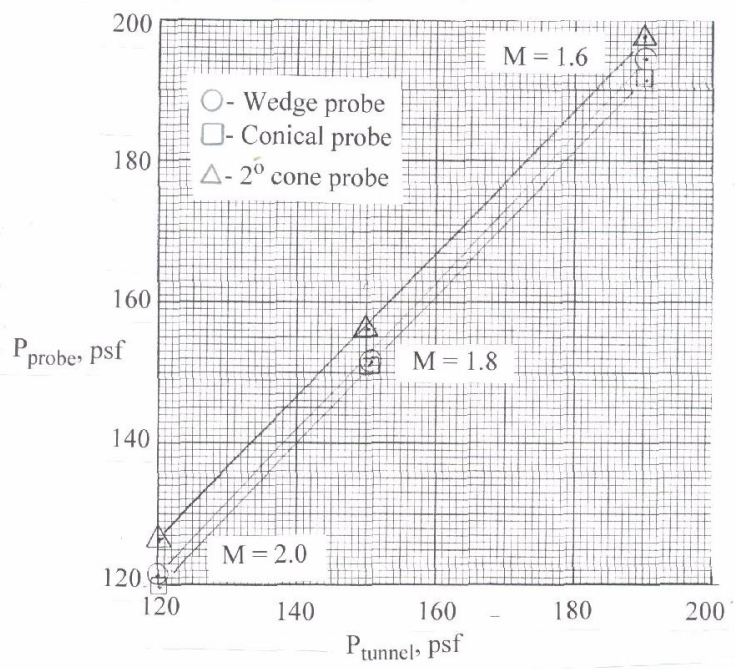

Figure 18. Comparison of probe measured pressure to wind tunnel values for three Mach numbers.

The data for the wedge and conical probe agree quite well considering that they are located 10 inches apart in a non-uniform free-stream, on the other hand, the data for the $2^{\circ}$ cone is about 3 to 3.5 percent higher. The fact that the 2 -degree cone reads high is because no account was made of the shock off its apex as for the other probes.

\section{Wind Tunnel Static Mach Number Measurements:}

Mach number determined by the wedge and conical probes, as well as for the $2^{\circ}$ cone are plotted in figure 19 as a function of the wind tunnel Mach number. The wedge and conical probe values agree at a nominal Mach number of 1.8, but the conical value is slightly higher at the other two Mach numbers. All values are higher than determined by the wind tunnel system.

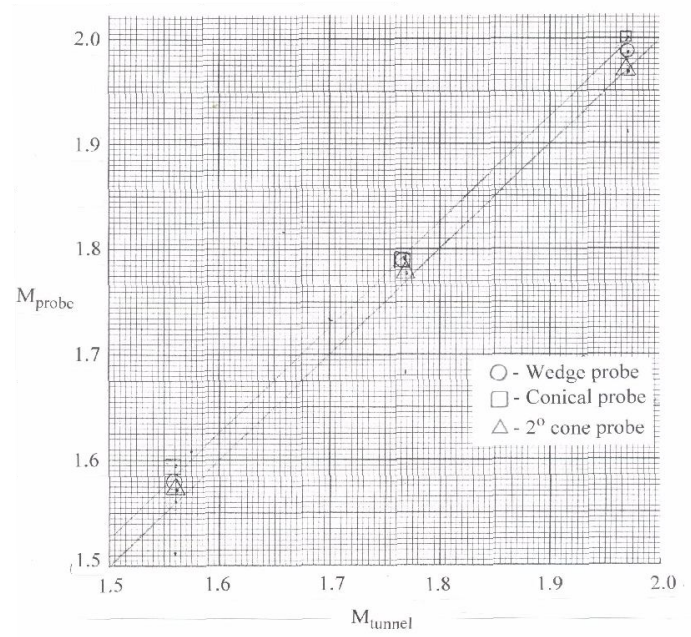

Figure 19. Comparison of probe measured Mach number to tunnel setting. 
Note that the wedge and conical probes use the total measured pressure at the gage location, while the Mach number of the tunnel system, and the calculation of that for the $2^{\mathrm{O}}$ cone, use a value determined upstream.

\section{Wind Tunnel Transient Pressures due to Shock Generator:}

Previous distributions created by moving the probes longitudinally through the flow field created by the generator (wall disturbance bump), over a distance of about 12 inches are discussed in this sub-section. For the wedge probe the leading edge shock from the generator is encountered at an $x$ of $\sim 3.0$ inches (see fig. 20) and it has a strength of 0.21 psi. It appears to have been resolved in 0.3 inches of the travel. The bow shock is followed by a gradual pressure recovery. There is a slight increase in pressures starting around $x=5.5$ inches which may be due to the secondary shock generator. The pressure recovery starts at an $\mathrm{x}$ of 9 inches and is made steeper by the presence of the secondary shock bump. Effectively the shock generator created a "flat-top pressure distribution.

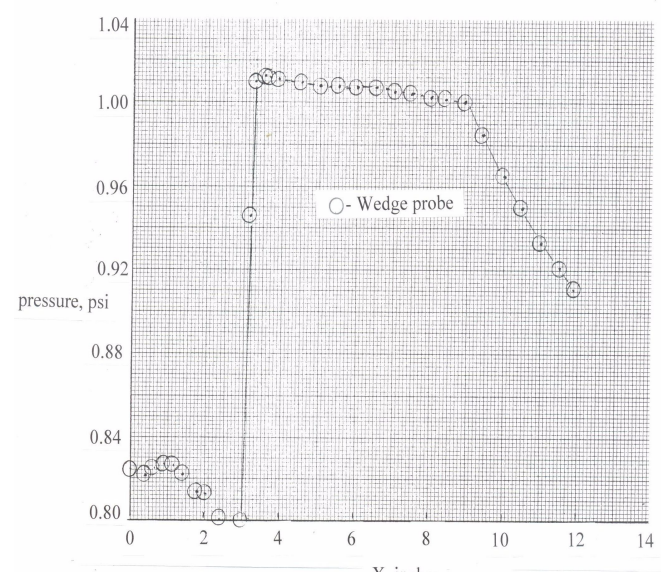

Figure 20. Response of wedge probe to disturbance bump shock.

The pressure distribution created by the shock generator (wall disturbance bump), as measured by the conical probe, is shown in figure 21 compared to that of the wedge. Since the apex of the cone of the conical probe is $\sim 1$ inch ahead of leading edge of the wedge, the shock from the generator is felt $\sim 1$ inch ahead of that felt by the wedge. Also, the shock is more smeared than for the wedge since the static pressures on the cone are $\sim 3 / 4$ inch downstream of the apex where the total pressure is measured. It may be recalled that total pressure measured by the wedge orifice is used for the cone. It appears that the shock jump is essentially the same as is the weak pressure recovery following the shock. The steep recovery beyond $x=9$ inches is smeared out relative to that of the wedge probe. This is due to the distance between the total and static pressure measurements on the conical surface. It should be remembered that in flight, which the conical probe is designed for, where the signatures are greater than the length of the aircraft, the smearing seen in these tests will not be a factor. 


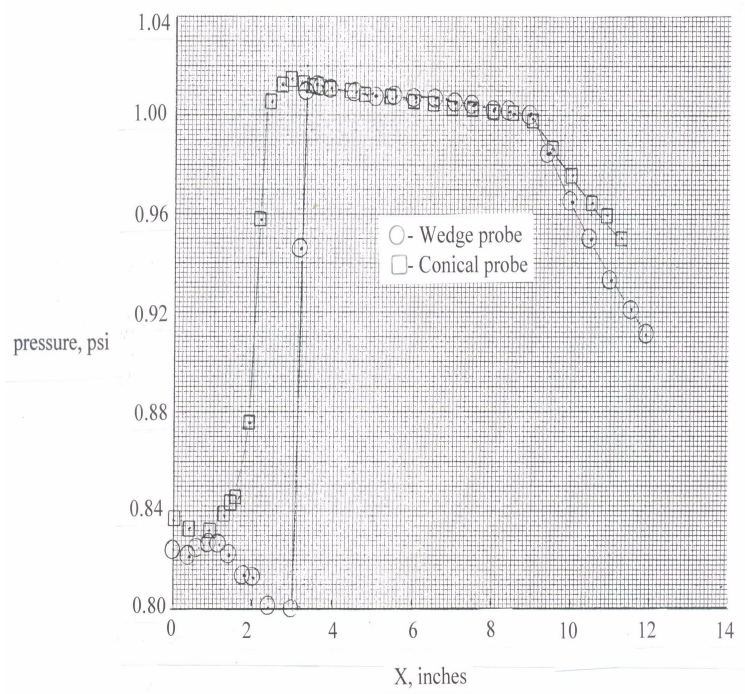

Figure 21. Response of wedge probe and conical probe to disturbance bump shock.

Figure 22 shows the pressure distribution, due to the shock generator (wall disturbance bump), measured by the $2^{\circ}$ cone compared to the wedge probe measurement. Its pressure sensor is located about a half-inch ahead of the leading edge of the wedge probe and, thus, it senses the shock jump ahead of the wedge by this amount. The gradual shock recovery downstream of the shock has about the same gradient as the wedge but the values are consistently 1 to $1-1 / 2$ percent lower than the wedge values. It is not clear if this is a result of the variable flow-field or the use of the tunnel-system total pressure measurement. Due to the fact that there is only one set of static sensors, the length of the weak pressure recovery is about the same as that for the wedge. However, the steep recovery beyond an $\mathrm{x}$ of $8-1 / 2$ inches is more "smeared" (i.e., a smaller gradient) than that of the wedge probe. This is a different phenomena from the smearing of the abrupt shock jump that is seen in this figure, as well as that shown in figure 7.

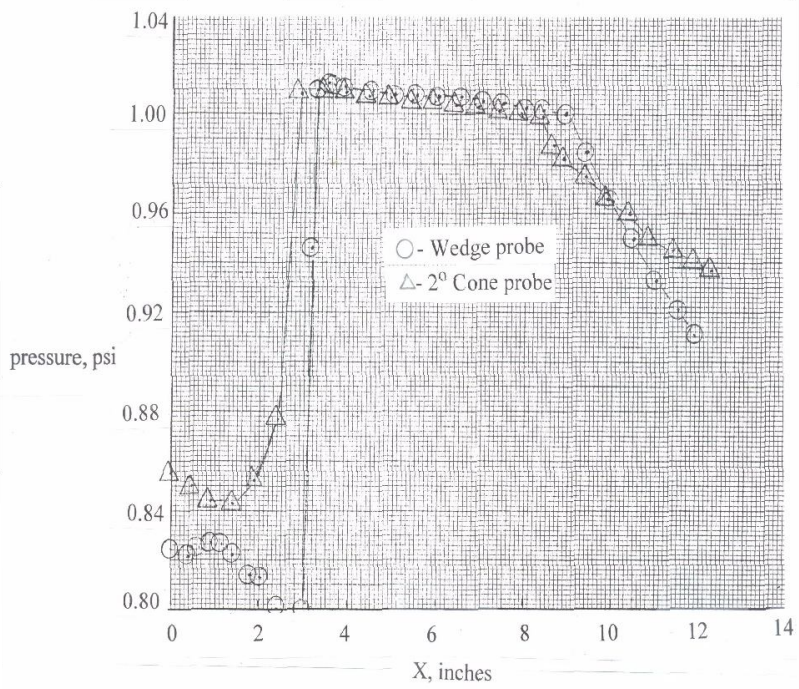

Figure 22. Response of wedge probe and $2^{\circ}$ cone probe to disturbance bump shock. 


\section{E. Wind Tunnel Transient Measurements of Mach Number:}

The variation of Mach number with distance was measured by the wedge and conical probes using the wedge-measured total pressure. The $2^{\circ}$ cone's static pressure was used with the tunnelsystem measured total pressure for this calculation.

Figure 23 shows the variation with $\mathrm{x}$ of the Mach number for the wedge probe. There is a slight increase in Mach number ahead of the shock jump due to the fact that all three pressure sensors are not exposed to the shock at the same time. Behind the shock the Mach number drops abruptly to 1.8. It is followed by a Mach recovery that lasts out to the end of the measurements. Note that there is an inflection beyond at $\mathrm{x}$ of 5 that is thought to be due to the secondary shock generator.

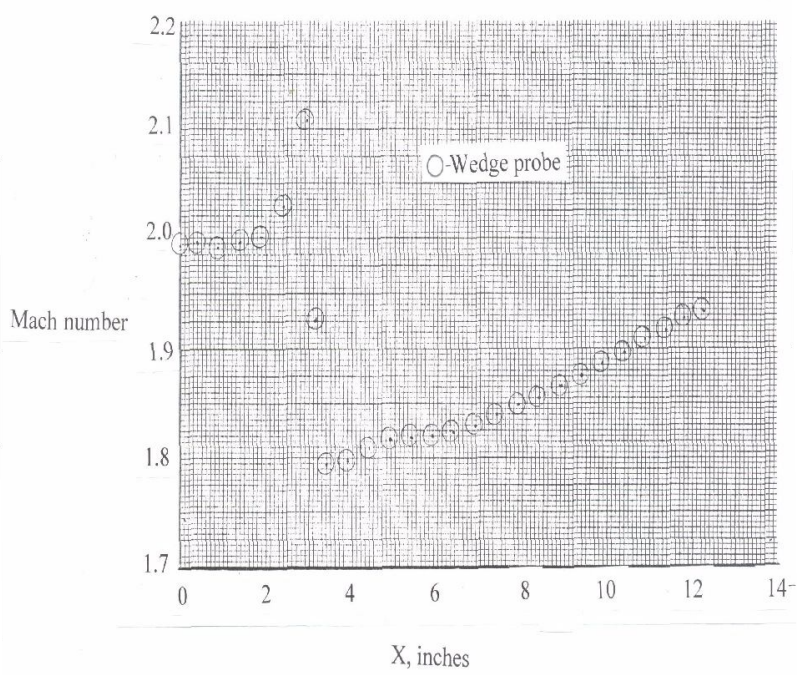

Figure 23. Variation of Mach number across wall disturbance shock as measured by wedge probe for tunnel nominal Mach number of 2.0

The $\mathrm{x}$ variation of the conical probe's Mach measurements is plotted in figure 24 along with that of the wedge probe. For these calculations the free stream total pressure measured by the wedge was used (as noted earlier) as it was for the pressure and flow angle measurements. Since this sensor is $\sim 1$ inch behind the apex of the cone, its measured values were translated forward by this amount to use in the conical calculations. Due to the different geometry of the cone and the location of its sensors there is more reduction of the gradient beyond an $\mathrm{x}$ of 8 inches as was the case for the pressure. Note that the pressures are used in the calculation of the Mach number. It is also clear from other measurements and the tunnel flow surveys that there are variations in total pressure (lateral and longitudinal) in the test region of these probes. One evidence of this is the difference in Mach number at $\mathrm{x}=0$. 


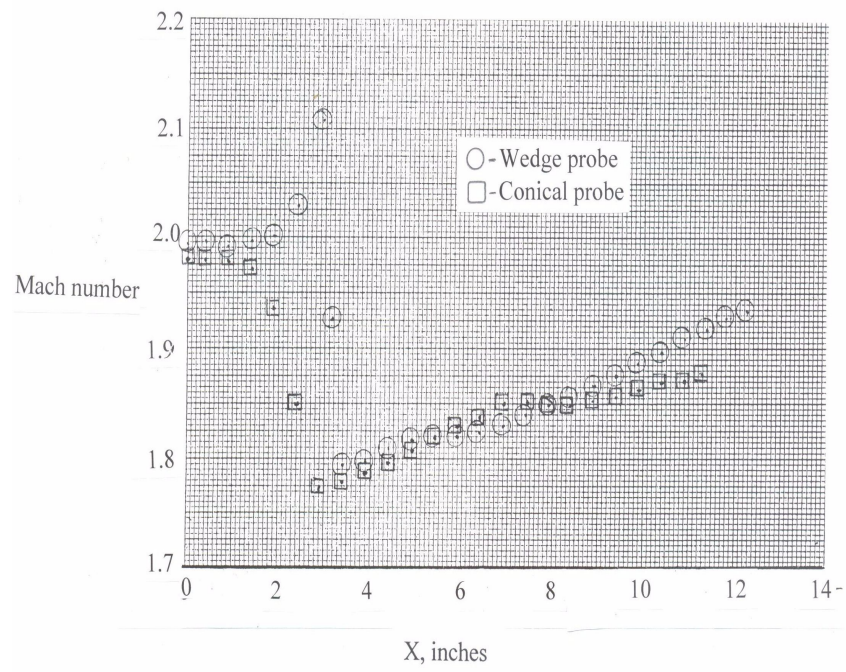

Figure 24. Variation of Mach number across wall disturbance shock as measured by wedge probe and conical probe for tunnel a nominal Mach number of 2.0.

While the $2^{\mathrm{O}}$ cone is not normally used for Mach number measurements (and it would not be useful in flight) it is possible to calculate Mach number using the $2^{\circ}$ cone measured static pressure and the tunnel measured total pressure (as noted earlier). The results are presented in figure 25 along with the wedge probe results. As with the other probes, the shock jump is smeared. It produced the highest Mach numbers downstream of the shock jump and the gradient in Mach number, beyond an $\mathrm{x}$ of 6.0 , is smaller than that of the wedge.

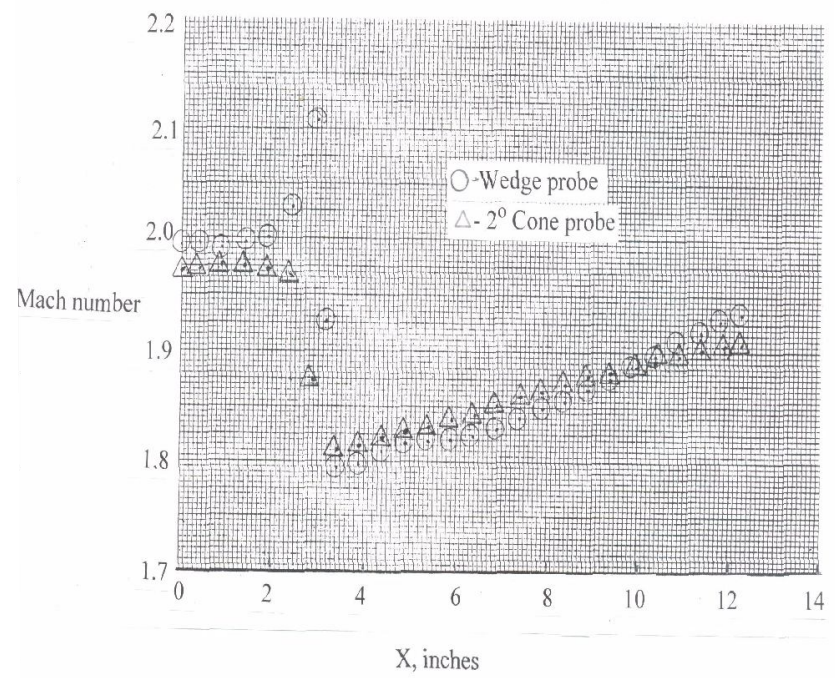

Figure 25. Variation of Mach number across wall disturbance shock as measured by wedge probe and $2^{\circ}$ conical probe for tunnel nominal Mach number of .2 .0 . 


\section{F. Temperature Measurements in the Conical Probe:}

The purpose of the temperature sensor inside the conical probe is to determine the free-stream stagnation temperature. To do this requires a measurement of the pressure in the channel ahead of the temperature sensor and the total pressure behind the normal shock at the apex.

These quantities are used in the equation

$$
T_{2}=\left(\frac{P_{t o t}}{P_{1}}\right)^{2 / 7} T_{\text {meas }}
$$

to calculate the stagnation temperature in the conical probe which is equal to that in the freestream. Where $T_{2}$ is the stagnation temperature inside the probe, $T_{\text {meas }}$ is the temperature measured by the temperature sensor inside the probe, $P_{\text {tot }}$ is pressure measured behind the bow shock at the cone apex, and $P_{1}$ is the pressure measured in the channel ahead of the temperature sensor.

Since the total pressure inside the cone was not measured accurately by the pressure sensor, and the fact that there was leakage problems (too much flow through the probe), it was not possible to utilize the above equation as intended. With no flow, or with a pin hole in the back, which allows a trivial amount of flow through the conical gage, the pressure gage in the channel indicated a pressure equal to the stagnation value and the temperature gage read $\sim 562^{\circ} \mathrm{R}$, which was exactly the free-stream stagnation temperature. So it appeared that with a proper total pressure measurement at the cone, and a cure for the leakage problem, that the free-stream stagnation temperature would be determined as designed.

\section{G. F-15 Shock Systems and Data Presentation:}

The location of the conical and wedge probes attached to a fixture, referred to as a CenterLine Instrumented Pylon (CLIP), under the fuselage of NASA's F-15 aircraft, is shown in figure 14a.

A sketch of the profile of this aircraft with shocks emanating from the various components, that one would expect to produce them, is shown in figure 26. As can be seen, depending on whether the CLIP shock is ahead of, or behind, the probes there will be four or three shocks ahead of the probes. Thus, there is no possibility that the probes there can measure anything resembling free stream quantities. There are, however, measurements of some of these quantities by the airplane system and comparisons can be made to show the differences.

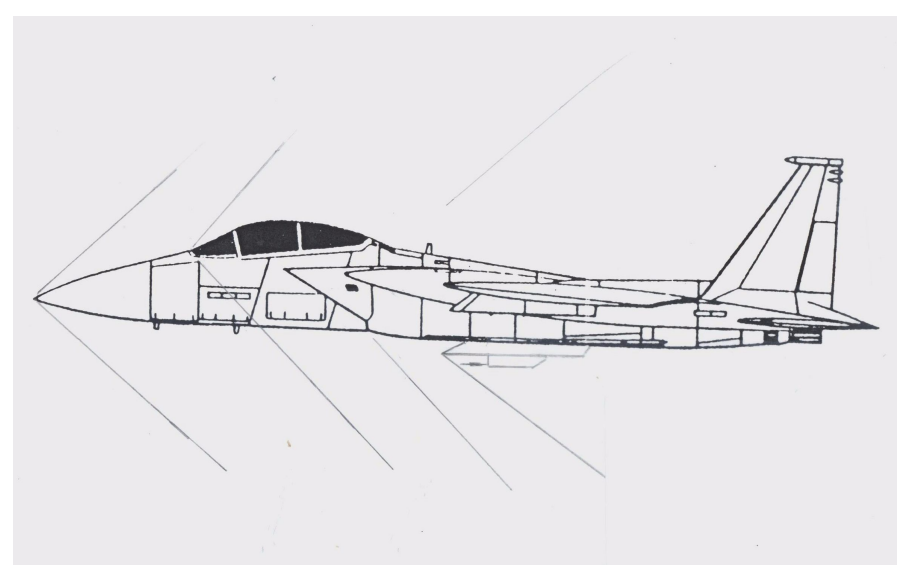

Figure 26. Sketch of the F-15 aircrft showing the shocks off the various aircraft components ahead of the CLIP 
Five test flights were made with different probe orientations on each flight. Table I below shows these orientations looking from in front of the probes along with the flight number designations for each of the five flights.

Table 1: Flight Test Program

\begin{tabular}{|c|c|c|}
\hline Flight & Date (2011) & $\begin{array}{l}\text { Probe Orientation } \\
\text { Looking from Front* }\end{array}$ \\
\hline 406 & March 25 & $T$ \\
\hline 407 & March 29 & \\
\hline 408 & March 30 & $T$ \\
\hline 409 & March 31 & \\
\hline 410 & April 1 & $T$ \\
\hline
\end{tabular}

*T indicates orientation of probes. In flight 406 , for example, the probes were mounted upside down and their top sides were on the bottom.

The subsequent data presentation will utilize data from flights 406, 407 and 409. As can be seen from the table in flight 407 the probes were inverted from the flight 406 orientation and in flight 409, the two probes switched locations from that of flight 406.

\section{H. Sensitivity of Data to Calibration Temperature of Pressure Gages:}

As noted in the introduction to this Results section, some of the Kulite pressure sensors are not fully compensated for temperature changes. Thus, the magnitude of the calculated flow variables will change depending on the temperature of the calibration used. To illustrate this fact, the calculated Mach number, static pressure, and total pressure variations with time for $70^{\circ} \mathrm{F}$ and $-50^{\circ} \mathrm{F}$ and for both the conical and wedge probes are given in figures 27 and 28, respectively. Also shown in figures 27 and 28 are the airplane system measurements of the free stream quantities. Figure 27a for Mach number determined by the conical probe for both the $70^{\circ} \mathrm{F}$ and $-50^{\circ} \mathrm{F}$ pressure sensor calibration shows that the Mach number level for both calibrations is less than free stream, as expected. The $-50^{\circ}$ calibration yields higher values of Mach number than the $70^{\circ} \mathrm{F}$ calibration. At the maximum Mach number of $\sim 1.85$ the $-50^{\circ} \mathrm{F}$ result is $\sim 2.0$ percent higher than the Mach number calculated using the $70^{\circ} \mathrm{F}$ calibration. Note that there is a shock passage over the gage at a time of $\sim 135$ seconds and another at $\sim 360$ seconds. Both occur between Mach numbers of $\sim 1.4$ and 1.6.

Static pressure measurements for the conical probe are plotted in figure $27 \mathrm{~b}$. Here the $70^{\circ} \mathrm{F}$ calibration is shown to yield higher values of static pressure for Mach numbers greater than 1.6 than for the $-50^{\circ} \mathrm{F}$ calibration by about 5 percent. Total pressure variations with time for the $70^{\circ} \mathrm{F}$ and $-50^{\circ} \mathrm{F}$ calibration agree fairly well with a difference between the two at the maximum value of $\sim 0.2$ percent. This is due to the fact that the calibration of the Kulite used to measure total pressure on the conical probe is well compensated for temperature. 
The effects of calibration temperature on the calculated flow quantities for the wedge probe are shown, as noted, in figure 28 . As with the conical probe, figure 28 a shows that the $-50^{\circ} \mathrm{F}$ calibration yields the higher values of Mach number with values about 5.5 percent higher in the area of the maximum Mach number. Note that there is a shock passage starting just beyond 250 seconds. It would appear that this shock is a part of the CLIP's shock system and, because the wedge probe leading edge is $\sim 1.0$ inch head of the conical probe's apex, it is able to sense it while the conical probe is not. .

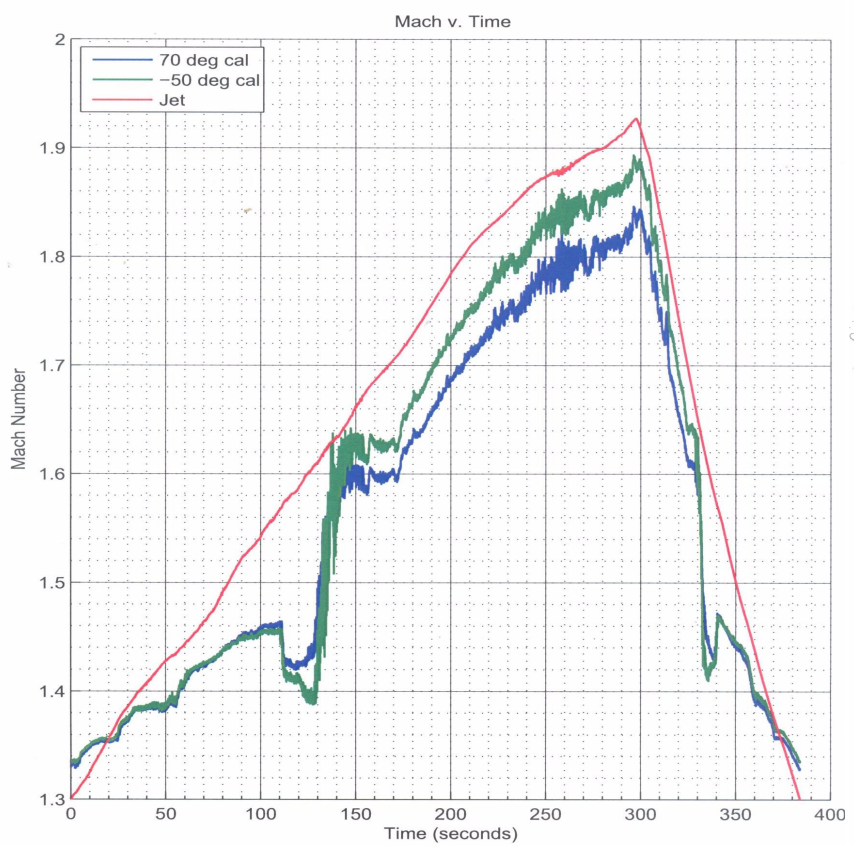

(a) Mach num44ber

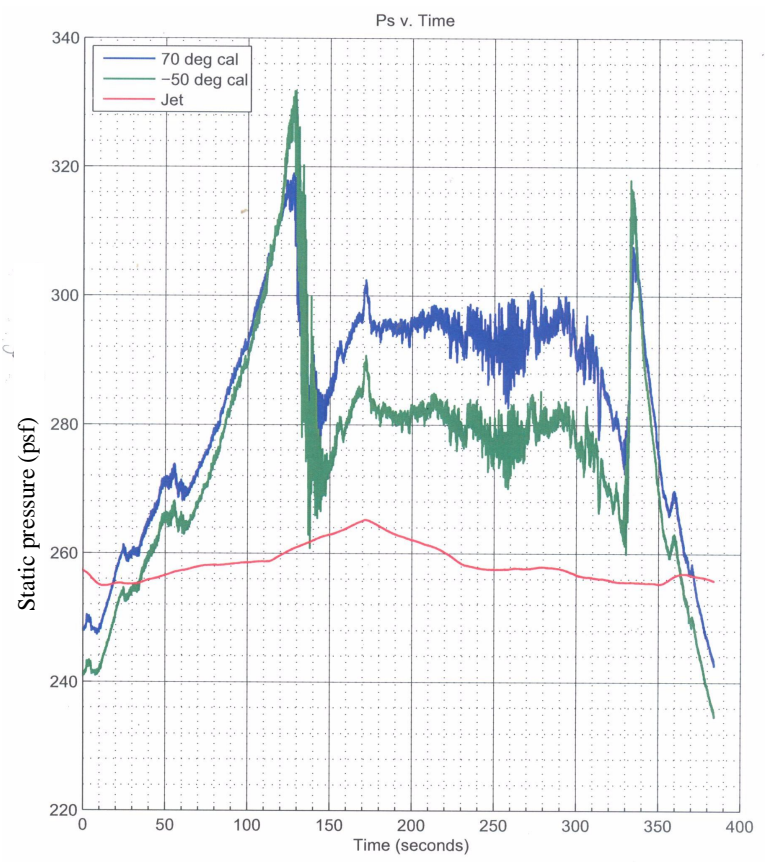

(b) Static pressure

Figure 27. Comparison of computed time variations of flow variables for the conical probe using pressure sensor calibrations for $70^{\circ} \mathrm{F}$ and $-50^{\circ} \mathrm{F}$

(c) Total pressure

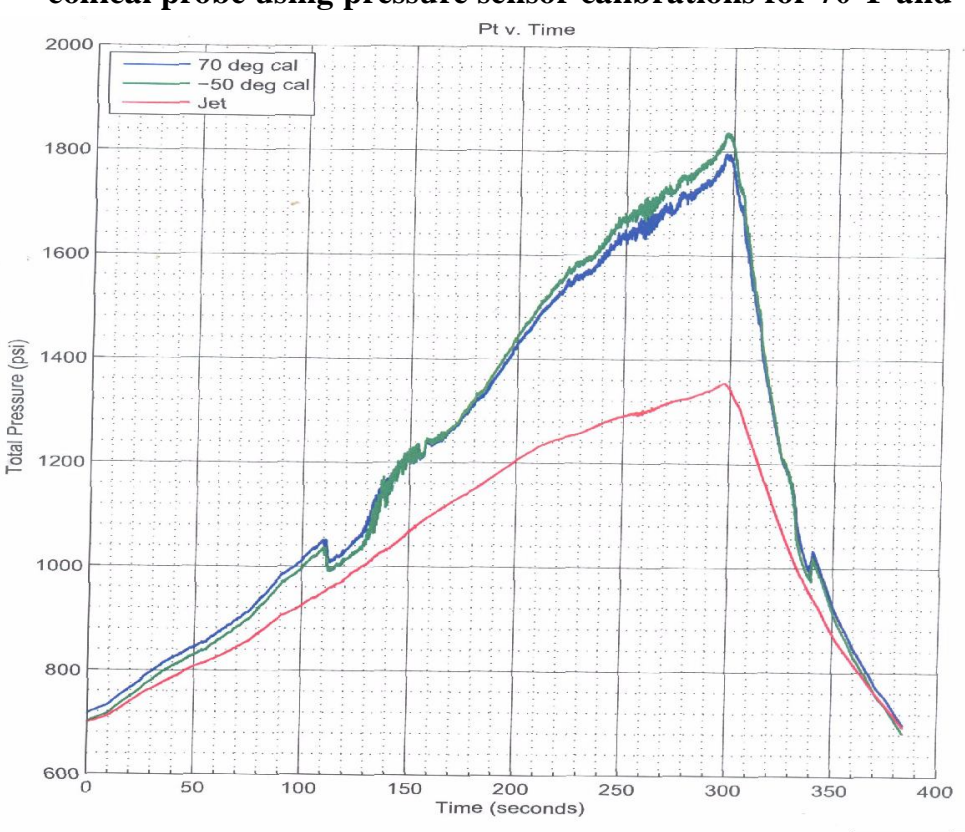

Figure 27. Concluded 
The static pressure variation with time for the two calibration temperatures, shown in figure $28 \mathrm{~b}$, show the $-50^{\circ} \mathrm{F}$ calibration to yield much lower values. The time variations are also different, apparently due to the more forward location of the wedge probe. Total pressures for the two calibrations, figure $28 \mathrm{c}$, are only about 3 percent different at the maximum value. This is due to the better temperature compensation of the 10 psi gage that was used to measure total pressure along with the tube on the bottom side of the wedge.

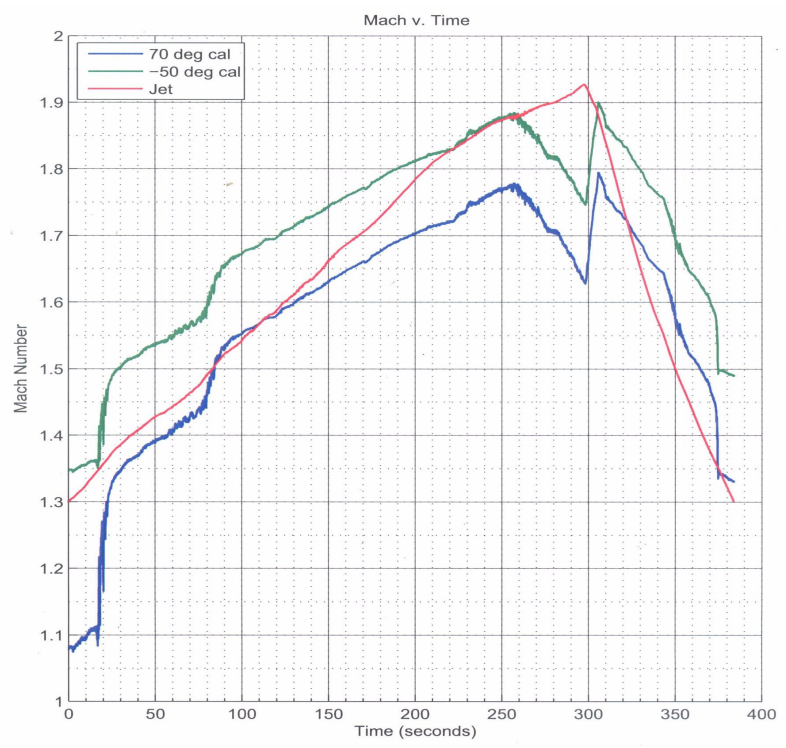

(a) Mach number

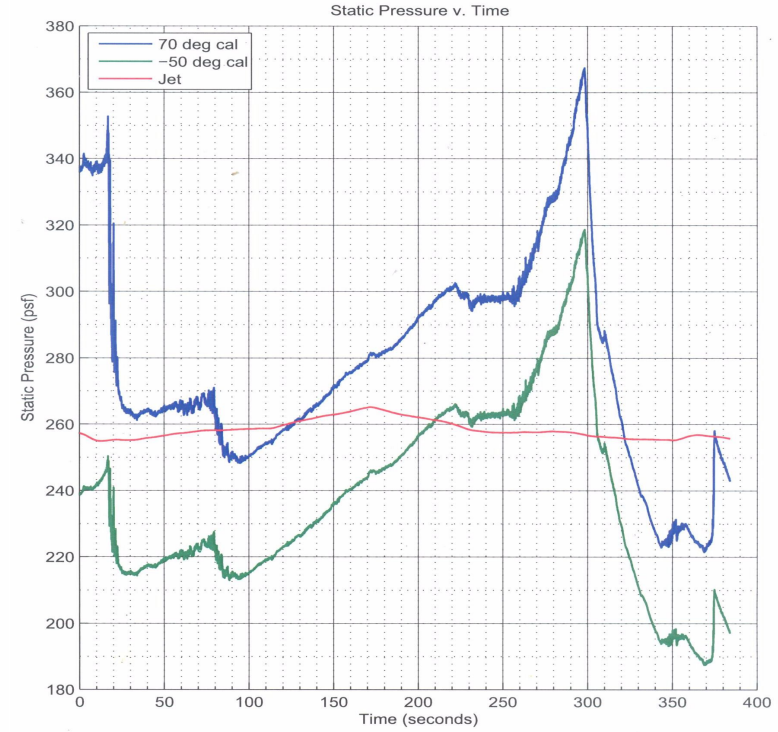

(b) Static pressure

Figure 28. Comparison of computed time variations of flow variables for the wedge probe using pressure sensors calibrations for $70^{\circ} \mathrm{F}$ and $-50^{\circ} \mathrm{F}$. Flight 406 .

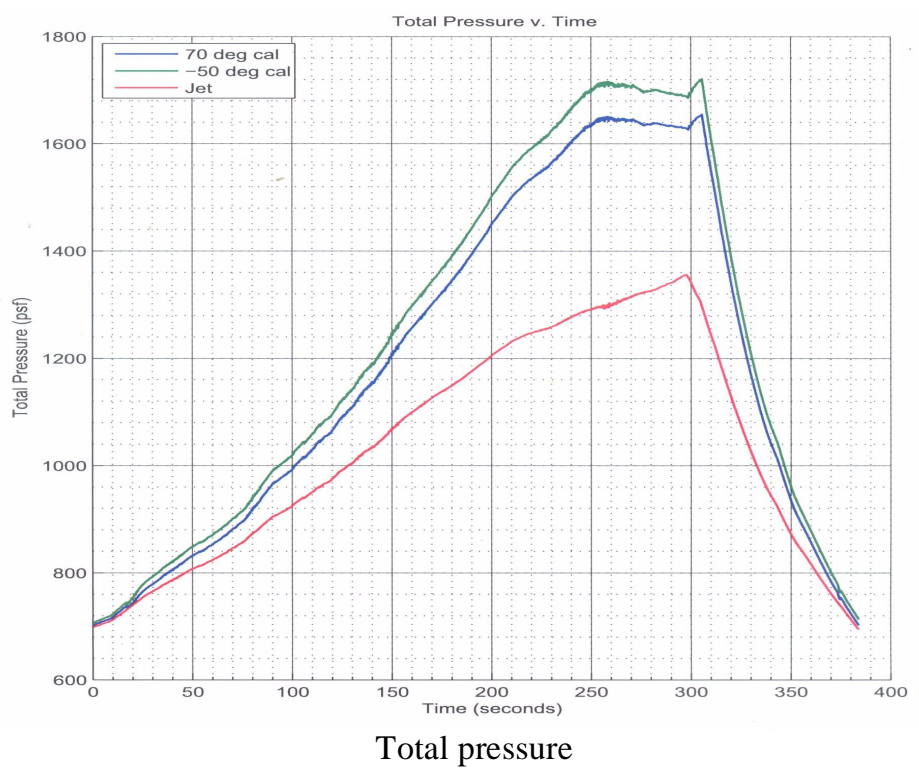

Figure 28. Concluded. 
To further illustrate the effect of the gage-calibration temperature, angle of attack, calculated using all four temperature calibrations, is plotted as a function of Mach number in figure 29. Figure 29a gives the data for acceleration and figure $29 \mathrm{~b}$ for deceleration. Note that the angle being measured is the local flow angle in the vertical plane by the wedge. Clearly the difference between the $140^{\circ} \mathrm{F}$ calibration and the $-50^{\circ} \mathrm{F}$ calibration are large and vary $\sim 3$ degrees at Mach 1.8 up to 6 degrees at Mach 1.4 during acceleration.

(a) Alpha wedge comparison Flt. 406 Acceleration

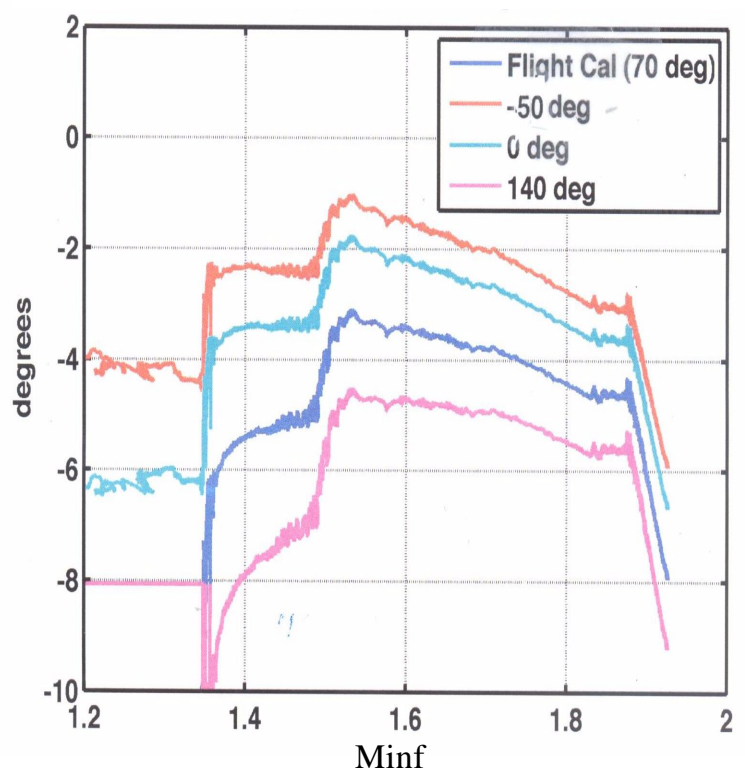

(b) Alpha wedge comparison Flt. 406 Deceleration

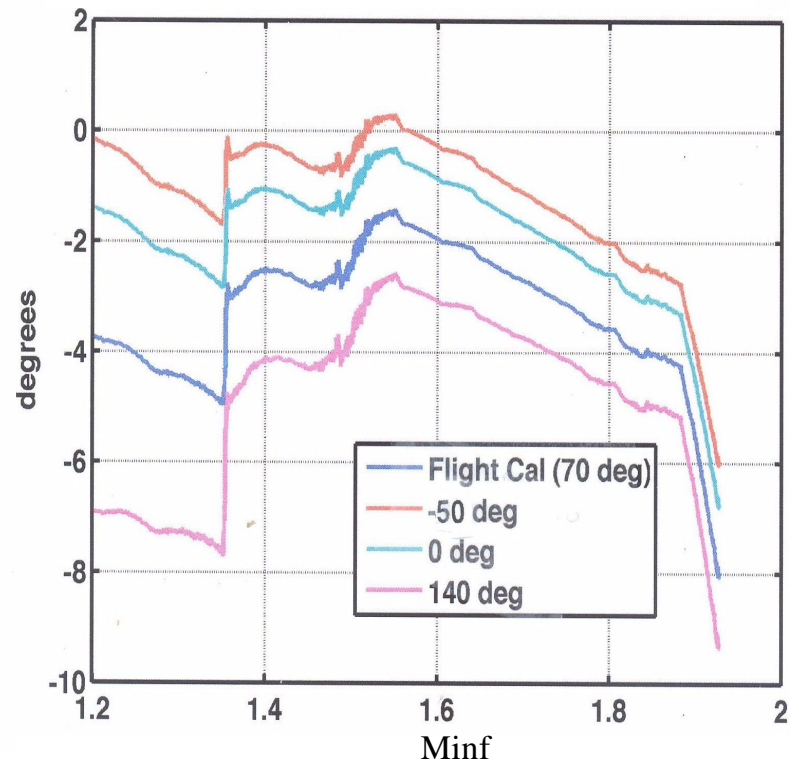

Figure 29. Wedge probe local alpha versus freestream Mach number for a set of representative temperatures and for acceleration and deceleration portions of fight 406 .

If one uses an interpolation scheme with the four calibrations available, and temperatures measured by the temperature gage in the conical probe, then the possibility of reducing the error, or uncertainty, in the calculated flow variables would seemingly be enhanced. While the temperature gage is not located where the Kulite sensors are, and there is some lag in the measurement of the changing environment, it should yield results better than using a single constant-temperature calibration. Figure 30 shows the results of such an exercise for both the acceleration and deceleration phases of flight 406. The improvement is clear and lends credit to the possibility that if one has calibrations for a range of temperatures and an accurate temperature measurement where the transducers are located, then accurate data will be produced. Ideally, one would like to have fully temperature-compensated gages and then no temperature measurement would be required. 


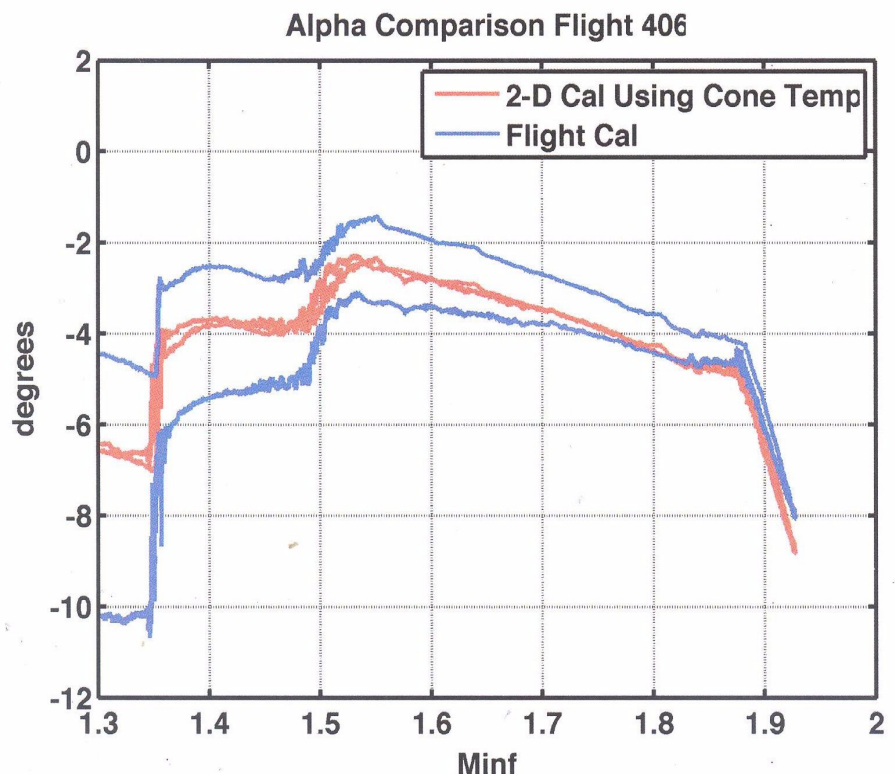

Figure 30. Wedge probe local alpha versus freestream Mach number by using an interpolative 2-dimensional calibration (pressure and temperature ).

\section{Comparison of Wedge and Conical Probe Data:}

It is evident from figures 27 and 28 that the wedge-probe results are more affected by the temperature of the calibration than the conical probe. Thus, when results from the two probes are compared, the differences in magnitude may not be accurate. However, differences in the variations with time are significant and are due to the approximately $1.0 \mathrm{inch}$ more forward location, as well as the higher resolutions of the wedge probe. In a subsequent figure, data from flight 407 using the $-50^{\circ} \mathrm{F}$ calibration data will illustrate some of these effects.

Mach number data for flight 407 (see fig. 31a) shows the earlier time passage of the shocks off the CLIP edges over the wedge probe at $\sim 116$ seconds versus that for the conical probe at $150 \mathrm{sec}-$ onds. Passage of these shocks in the other direction occurs at 320 seconds and 350 seconds for the conical and wedge probes, respectively. There is also a shock that passes over the wedge probe as in flight 406 (see fig. 28a), starting at around 250 seconds and then it goes back over the wedge during deceleration, ending its "trip" at 300 seconds. Apparently the conical probe is just beyond this shock. 


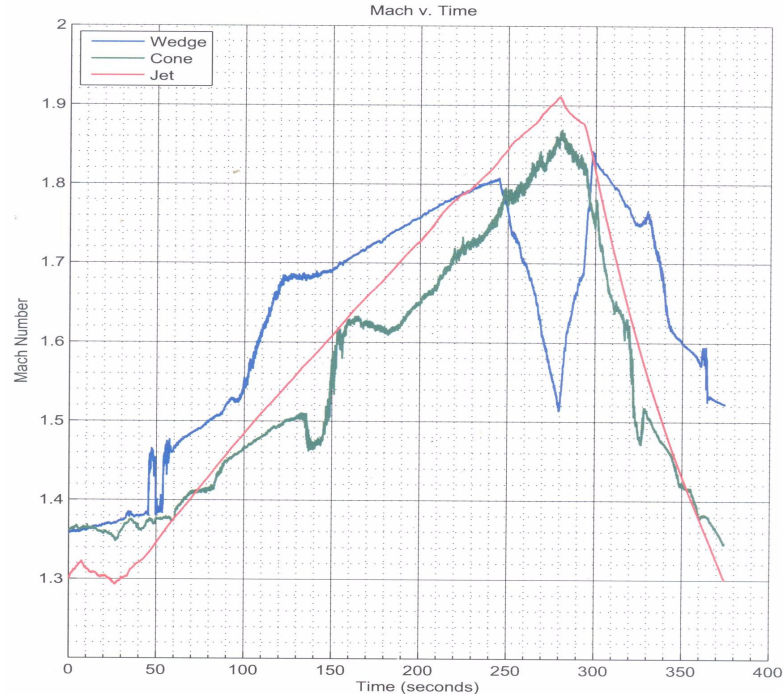

(a) Mach number.

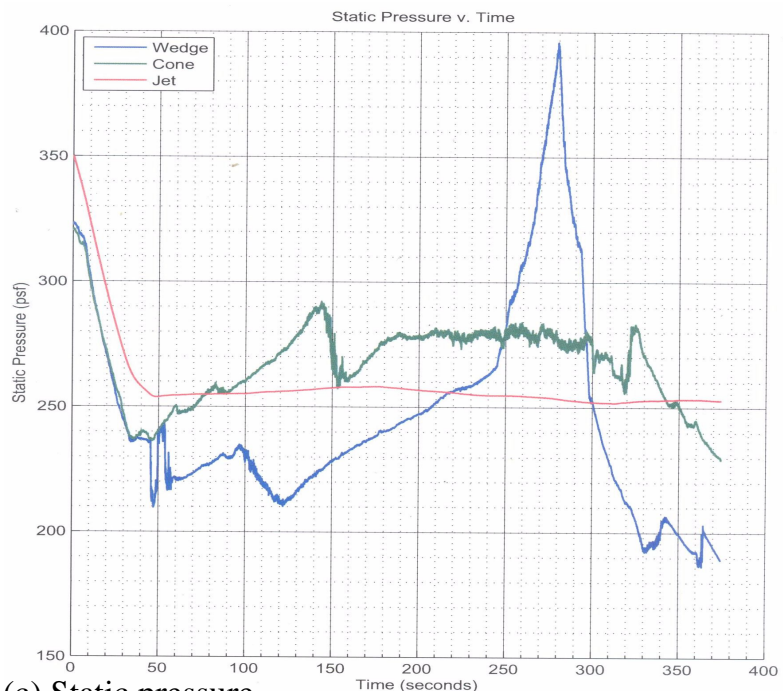

(c) Static pressure.

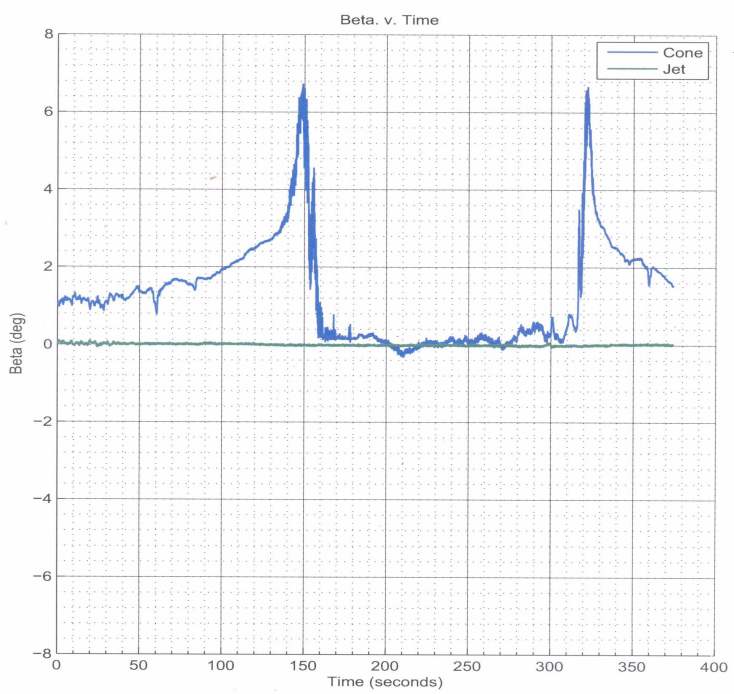

(b) Beta (lateral) angle.

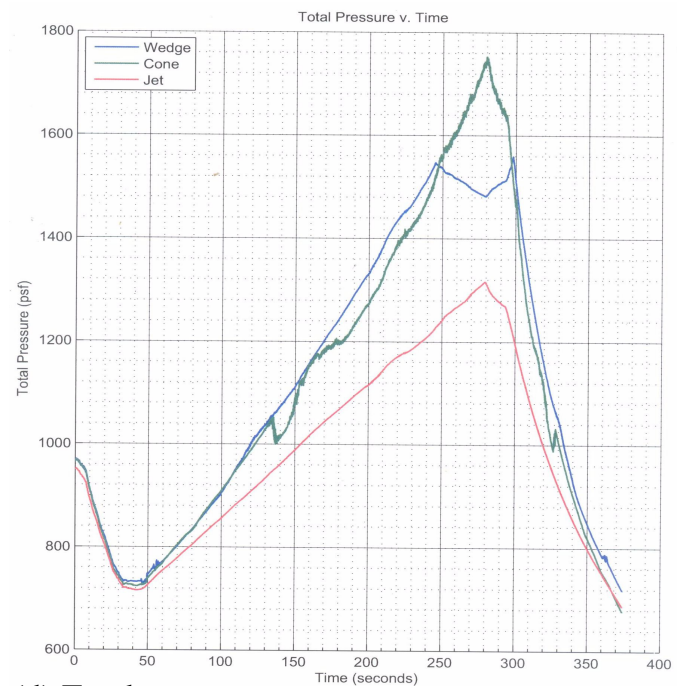

(d) Total pressure.

(e) Alpha (pitch) angle.

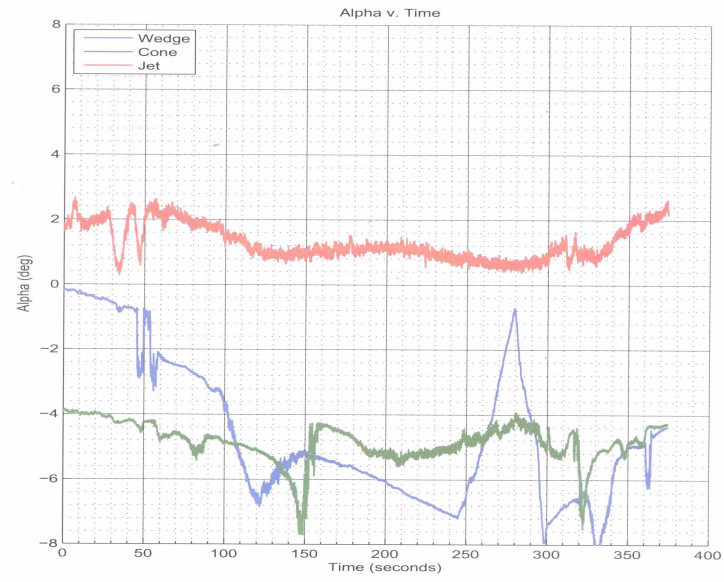

Figure 31. Comparison of computed time-variation of flow variables for the wedge and conical probes using the $-50^{\circ}$ calibration of the pressure sensors. 
The conical probe measures sideslip or $\beta$ angle, the wedge probe does not. Figure $31 \mathrm{~b}$, again for flight 407, shows this measurement as a function of time. Noteworthy in this figure is the large change or spikes in the $\beta$ angle as the shock off the edge of the CLIP passes.

Static pressure differences between the wedge and conical probe measurements are evident in figure 31c. In addition to the changes that occur during shock passage, the higher level of static pressures measured by the wedge probe versus those of the conical probe between the times of 250 and 300 seconds are due to a CLIP shock passing over the wedge probe. Total pressure differences in this same time interval are evident in figure $31 \mathrm{~d}$.

Angle-of-attack for the two probes is plotted in figure 31e. The differences mirror those of Mach number where the shock passage at times of 100 and 150 seconds produce spikes in the angle-of-attack variation. The shock that impacts the wedge probe at 250 seconds, and goes away at 300 seconds, also produces a large spike in alpha as it did at Mach number.

\section{J. Temperature Variations:}

Flight measurements of temperature inside the conical probe, labeled $\mathrm{T}_{\text {measured }}$ in figure 32 , are converted to stagnation temperature, $\mathrm{T}_{2}$, using the equation in Section $\mathrm{F}$ and the total pressure at the cone apex and the static pressure measurement in the channel of the temperature sensor (see fig. 32). Since the stagnation temperature inside the cone $\left(\mathrm{T}_{2}\right)$ is the same as in the "freestream" stagnation temperature $\left(\mathrm{T}_{\mathrm{s}}\right)$, it is possible to calculate freestream static temperature $\left(\mathrm{T}_{\mathrm{INF}}\right)$ using

$$
T_{I N F}=\frac{T_{s}}{1+\left(\frac{\gamma-1}{2}\right) M_{\infty}^{2}}
$$

and the local Mach number determined earlier. Note that the term free-stream above means the flow just ahead of the conical probe and not that ahead of the airplane. Also, it is important to recognize that as the flow is processed by the shocks ahead of the CLIP (see fig. 26), that they cause an increase in its temperature. So the fact that $\mathrm{T}_{2}$ is higher than the airplane total, labeled Jet, is no surprise. There is no way to determine if the increment between the jet total temperature and that determined by the conical probe is accurate or not, short of a CFD study or additional temperature measurements. With the determination of the Mach number and temperature just ahead of the conical probe, the speed-of-sound, velocity, and density would also be calculated. 


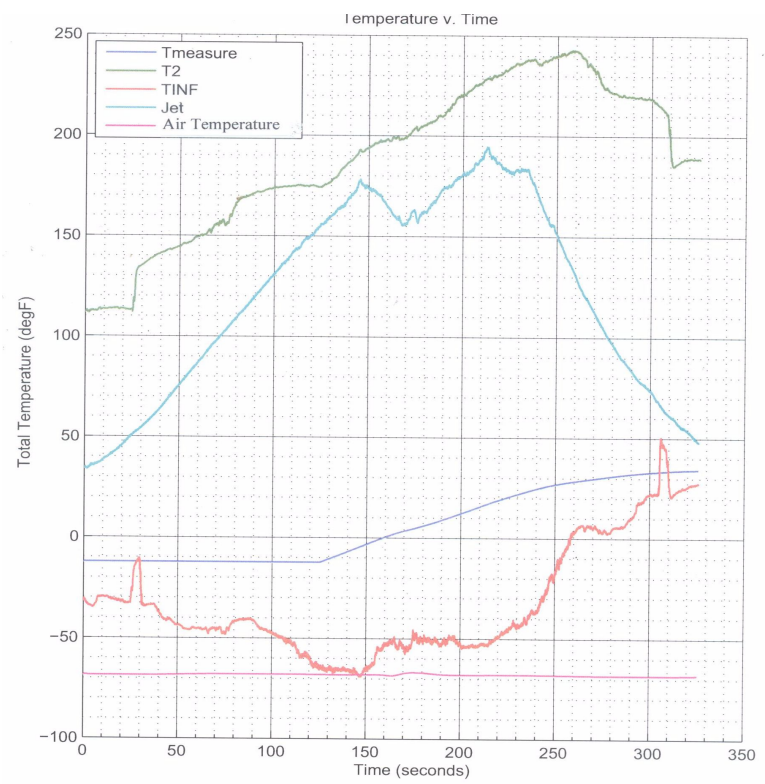

Figure 32. Variation of the temperature with time inside ( $\mathbf{T}_{\text {measured }}$ and $\left.\mathbf{T}_{\mathbf{2}}\right)$ and ahead of the conical probe $\left(T_{\text {inf }}\right)$, as well as those in the air ahead of the F-15 (Air temperature) and behind the bow shock off the front of the F-15 aircraft (labeled Jet).

The thin horizontal line at the bottom of figure 32, labeled air temperature, was obtained from a balloon flight on the day of flight 409. It is near constant, since the time period of these measurements was on the order of five minutes and the altitude changed very little.

\section{Summary Remarks}

Conical and wedge probes designed to measure free-stream flow variables have been tested in the wind tunnel and in flight. Wind tunnel tests were carried out in the NASA Langley Research Center's Unitary Plan Wind Tunnel and the flight tests on a fixture attached to the lower fuselage of a NASA Dryden Flight Research Center F-15 aircraft. These tests were termed functional, check-out, or structural-integrity tests. Free stream measurements were made in the wind tunnel tests successfully, while the flight tests, because of the location of the probes, only allowed the measurement of the local flow variables ahead of the probes.

As expected, the wedge probe provided the most accurate data. The close proximity of its sensors made for the least smearing of the gradients of all the flow quantities. In both the wind tunnel and flight tests the problem of "leaks" at the back of the conical probe caused the flow velocity over the temperature sensor inside the conical probe to be uncertain and/or excessive. Nevertheless, the internal measurements effected by this flow were used to determine the total pressure inside the conical probe and, consequently, in the free stream.

\section{A. Wind Tunnel Tests:}

The conical probe measurements were hampered by the total pressure not being accurately measured by the sensor located inside the probe itself. The use of the total pressure measured by the wedge for the total pressure at the cone enabled the calculation of the flow quantities of interest using the static pressures on the cone. However, there are gradients of all the flow quantities in the test section, as noted in the paper, and with the wedge and conical probes separated laterally 
by 10 inches the accuracy of the conical probe calculations will incur a small "error." This error is of particular concern when the total pressure (from the wedge) is used in combination with the static pressure in the channel containing the temperature sensor to correct the measurements made by the temperature sensor to yield the stagnation temperature. As noted in the section entitled "Description of New Wedge and Conical Probes," the total pressure measurement has been moved from the cup inside the probe to the apex of the cone for the flight tests.

The smearing of the transient variations of pressure and Mach number with longitudinal distance for the $15^{\circ}$ conical probe and the $2^{\circ}$ cone is greater than the wedge probe, as noted, but in the case of the former this phenomena is caused by the size (diameter) of the probe which enables the inclusion of the temperature sensor. In the flight environment where aircraft and their signatures are 50 or 100 feet in length or more, this is not a problem. For the $2^{\circ}$ cone, which is only used in tunnel measurements, the smearing is less for large models than for small. There is a builtin error, however, due to the pressure sensors being on the surface of a $2^{\circ}$ cone and its shock flowfield as well as the boundary layer on its surface.

\section{B. Flight Tests:}

The flight tests were carried out successfully with five flights being conducted. Anomalies between the data taken during ascent and data taken during descent of the same flight highlighted the effects that temperature was having on the calculated quantities. Further analysis showed that the Kulites' room-temperature calibrations were the problem, since automatic compensation for the lower temperatures were not being done. Subsequent calibrations of the nine Kulite sensors for temperatures of $-50^{\circ} \mathrm{F}, 0^{\circ} \mathrm{F}, 70^{\circ} \mathrm{F}$ and $140^{\circ} \mathrm{F}$ showed that some gages were well compensated and others were not. Use of these calibrations showed that significant differences occurred between the calculated flow variables at $70^{\circ} \mathrm{F}$ and $-50^{\circ} \mathrm{F}$. Figures included in the paper show these differences and point out the need for an accurate temperature measurement where the Kulite sensors are located, along with calibrations for a range of temperatures, or, ideally, sensors that are truly temperature compensated. A third possibility is to house the sensors in a temperature controlled enclosure.

\section{Future Tests:}

The conical and wedge probes were intended to be put on the front of the aircraft fuselage so that real free stream flow variables could be measured. With a solution to the temperature sensitivity problem of the pressure sensors and the higher than expected flow velocity through the conical probe, it appears that the probes would be ready for such a flight.

\section{References}

1. Taylor, G. I.; and Maccoll, J. W.: The Air Pressure on a Cone Moving at High Speeds. I and II. Proc. Royal Soc. (London) ser A, Vol. 139, No. 838, Feb. , 1933.

2. Maccoll, J. W.: The Conical Shock Wave Formed by a Cone Moving at a High Speed. Proc. Royal Soc. (London) ser A Vol. 159, No. 898, April 1. 1937.

3. Staff of Ames 1-by-30 foot Supersonic Wind Tunnel Section: Notes and Tables for use in the Analysis of Supersonic Flow. NACA TN 1428, 1947.

4. Moeckel, W. E; and Connors, J. F.: Charts for the Determination of Supersonic Air Flow Against Inclined Planes and Axially Symmetric Cones. NACA TN 1373, 1947.

5. Stone, A.H.: On Supersonic Flow Past a Slightly Yawing Cone. II Jour. Math. and Phys. Vol. XXX, No. 4, Jan. 1952. 
6. Massachusetts Institute of Technology, Dept. of Elec. Eng., Center of Analysis. Tables of Supersonic Flow Around Cones at Large Yaw by the Staff of the Computing Section Under the Direction of Zdenek Kopal. Tech. Rept. No. 5, Cambridge, 1949.

7. Ames Research Center Equations, Tables and Charts for Compressible Flow. NASA Report 1135, 1953.

8. Bobbitt, Percy J.; and Darden, Christine M.: A Wedge Shaped Supersonic Flow Field Probe. High Speed Research Sonic Boom, Vol. II. NASA CP 10133, May 1993.

9. Ferri, Antonio: Elements of Aerodynamics of Supersonic Flows. The MacMillan Company, New York, 1949.

10. Cubbison, Robert W.; and Melearson, Edward T.: Water Condensation Effects of Heated Vitiated Air on Flow in a Large Supersonic Wind Tunnel. NASA TM X-1636, 1968.

11. Gorlin, S.M.; and Slezinger: Wind Tunnels and Their Instrumentation. NASA TTF-346, 1966.

12. Bryer, D. W.: Pressure Probes Selected for Three-Dimensional Flow Measurements. ARC Rep. and Mem., No. 3037, 1958.

13. Carlson, Harry W.: Measurements of Flow Properties in the Vicinity of Three Wing-Fuselage Combinations at Mach Numbers of 1.61 and 2.01. NASA TM-64, 1959.

14. Putnam, Lawrence E.; and Capone, Francis J.: Experimental Determination of Equivalent Solid Bodies to Represent Jets Exhausting Into a Mach 2.20 External Stream. NASA TN D5553, Dec. 1969.

15. Carlson, Harry W.: Correlation of Sonic-Boom Theory With Wind-Tunnel and Flight Measurements. NASATR R-213, Dec. 1964.

16. Carlson, Harry W.; Mack, Robert J.; and Morris, Odell A.: A Wind-Tunnel Investigation of the Effect of Body Shape on Sonic-Boom Pressure Distributions. NASA TN D-3106, Nov. 1965.

17. Miller, David S.; and Morris, Odell A.: Wind-Tunnel Investigation of Sonic-Boom Characteristics of Two Simple Wing Models at Mach Numbers from 2.3 to 4.63. NASA TN D-6201, April 1971.

18. Shrout, Barrett L.; Mack, Robert J.; and Dollyhigh, Samuel M.: A Wind-Tunnel Investigation of Sonic-Boom Pressure Distributions of Bodies of Revolution at Mach 2.96, 3.83 and 4.63. NASA TN D-6195, April 1971.

19. Carlson, Harry W.; and Mack, Robert J.: A Study of the Sonic-Boom Characteristics of a Blunt Body at a Mach Number of 4.14., NASA TP 1015.

20. Carlson, Harry W.; and Mack, Robert J.: A Wind-Tunnel Study of the Applicability of FarField Sonic-boom Theory to the Space Shuttle Orbiter. NASA TP 1186, June 1978.

21. Mack, Robert J.; and Darden, Christine M.: Wind-Tunnel Investigation of the Validity of a Sonic-Boom-Minimization Concept., NASA TP 1421. October 1979.

22. Carlson, Harry W.: An Investigation of the Influence of Lift on Sonic-Boom Intensity by Means of Wind-Tunnel Measurements of the Pressure Fields of Several Wing-Body Combinations at a Mach Number of 2.01. NASA TN D-881, July 1961,

23. Carlson, Harry W.: An Investigation of Some Aspects of the Sonic Boom by Means of WindTunnel Measurements of Pressures About Several Bodies at a Mach Number of 2.01. NASA TN D-161, December 1959. 


\section{Appendix A}

\section{Data Reduction Equations and Solution Procedure Required to Derive the Freestream Variables}

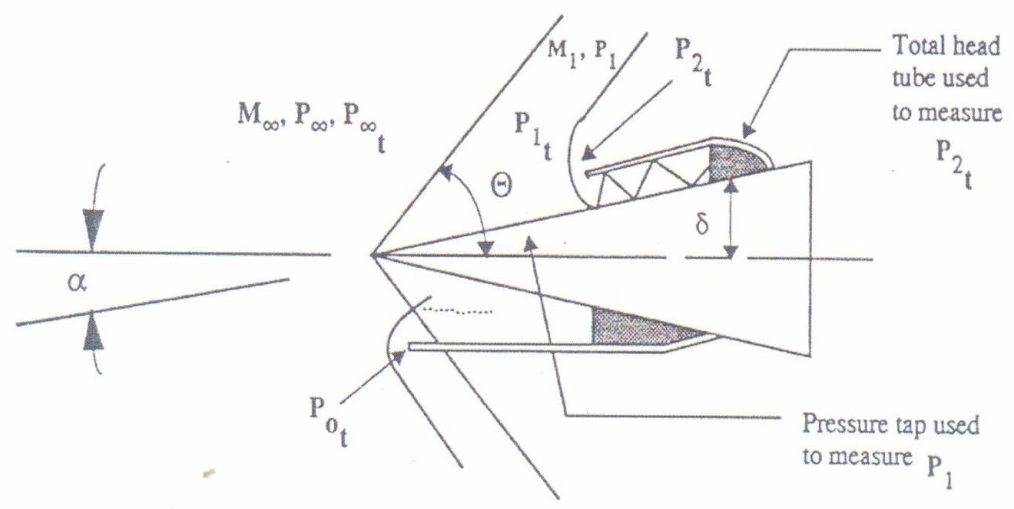

o $\quad M_{\infty}, P_{\infty}$ and $\alpha$ are flow quantities that the probe is required to determine.

o $\quad P_{1}, P_{o}$ and $P_{2}$ are measured (see sketch).

o $\quad \mathrm{M}_{1}$ is calculated from $\mathrm{P}_{1}$ and $\mathrm{P}_{2, \mathrm{t}}$.

o With $\mathrm{P}_{1}, \mathrm{P}_{\mathrm{o}, \mathrm{t}}$ and $\mathrm{M}_{1}$ known, $M_{\infty} \Theta, P_{\infty}$ and $\alpha$ can be calculated using the iterative procedure described below.

Procedure:

1. Measure $P_{1}, P_{o}$ and $P_{2}$

2. Calculate $\mathrm{M}_{1}$ from $\frac{P_{1}}{P_{2}}=\left(\frac{7 M_{1}^{2}-1}{6}\right)^{5 / 2}\left(\frac{5}{6 M_{1}^{2}}\right)^{7 / 2}$

See discussion at the end of this Appendix for the iterative procedure for calculating $M_{1}$.

3. With $\mathrm{M}_{1}$ and $\mathrm{P}_{1}$ known, calculate $\mathrm{P}_{1, \mathrm{t}}$ from $\frac{P_{1_{t}}}{P_{1}}=\left(\frac{M_{1}^{2}+5}{5}\right)^{7 / 2}$

4. Using oblique shock relations, one can write $\frac{P_{1_{t}}}{P_{1}}=\left[\frac{(6 \xi+1)\left(M_{\infty}^{2}+5\right)}{5 \xi(\xi+6)}\right]^{7 / 2}$ or solving for $M_{\infty}^{2} \quad M_{\infty}^{2}=\frac{5 \xi(\xi+6)}{6 \xi+1}\left(\frac{P_{1_{t}}}{P_{1}}\right)^{2 / 7}-5$ 
with $\xi=\frac{P_{1}}{P_{\infty}}$

5. Make initial guess for $\xi$ using curve fits for solutions to oblique shock relations found in reference 3 for selected semi-wedge angle of $8^{\mathrm{o},} \cdot \xi=1.41625-0.04 M_{\infty, f}+0.055 M_{\infty, f}^{2}$ where $M_{\infty, f}=72-\sqrt{5161.538-153.846 M_{1}}$

6. With first guess for $\xi\left(=\xi_{1}\right)$ calculate $M_{\infty, 1}^{2}$ from

$$
M_{\infty, 1}^{2}=\frac{5 \xi_{n}\left(\xi_{n}+6\right)}{6 \xi_{n}+1}\left(\frac{P_{1_{t}}}{P_{1}}\right)^{2 / 7}-5
$$

7 Then calculate

$$
\left(\frac{P_{1}}{P_{o}}\right)_{n}=\frac{5 \xi_{n}}{6 M_{\infty, n}^{2}}\left(\frac{35 M_{\infty, n}^{2}-5}{36 M_{\infty, n}^{2}}\right)^{2.5 /}
$$

If

$$
\left|\left(\frac{P_{1}}{P_{o}}\right)_{E}-\left(\frac{P_{1}}{P_{o}}\right)_{n}\right|>0.000001
$$

from experiment

Then calculate next guess of $\xi$ from

$$
\xi_{n+1}=\xi_{n}+\frac{\left[\left(\frac{P_{1}}{P_{o}}\right)_{E}-\left(\frac{P_{1}}{P_{o}}\right)_{n}\right]}{2\left(\frac{P_{1}}{P_{o}}\right)_{E}}
$$

and substitute it in from equation (1) for new $M_{\infty, n}$, which in turn is substituted in equation (2) above and check is repeated. 
8. If $\left|\left(\frac{P_{1}}{P_{o}}\right)_{E}-\left(\frac{P_{1}}{P_{o}}\right)_{n}\right|>0.000001$ record $M_{\infty, n}$ then compute

$$
P_{\infty}=\frac{P_{1}}{\xi_{n}}
$$

and

$$
P_{\infty, t}=P_{\infty}\left(1+0.2 M_{\infty, n}^{2}\right)^{7 / 2}
$$

Compute $\Theta$ from

$$
\Theta=\sin ^{-1} \sqrt{\frac{6 \xi_{n}+1}{7 M_{\infty, n}^{2}}}
$$

and $\delta-\alpha$ from

$$
\delta-\alpha=\sin ^{-1} \sqrt{\frac{6 \xi_{n}+1}{7 M_{\infty, n}^{2}}}-\sin ^{-1} \sqrt{\frac{\xi_{n}+6}{7 M_{1}^{2} \xi_{1}}}
$$

and $\alpha$ from

$$
\alpha=\delta-(\delta-\alpha)
$$

with $\delta=0.1396$ radius and $(\delta-\alpha)$ from equation (6).

\section{THE CALCULATION FOR $M_{1}$ FOLLOWS:}

Formula for first guess of $\mathrm{M}_{1}\left(=\mathrm{M}_{1,1}\right)$. From normal shock relations

$$
\frac{P_{2}}{P_{1}}=\left(\frac{6}{7 M_{1}^{2}-1}\right)^{5 / 2}\left(\frac{6 M_{1}^{2}}{5}\right)^{7 / 2}
$$


with

$$
\begin{array}{r}
7 M_{1}^{2} \gg 1 \\
7 M_{1}^{2}-1 \rightarrow 7 M_{1}^{2}
\end{array}
$$

then

$$
2 \frac{P_{2}}{P_{1}} \sim\left(\frac{36}{35}\right)^{5 / 2} \frac{6}{5} M_{1}^{2}
$$

and

$$
M_{1}^{2} \approx \frac{5}{6}\left(\frac{36}{35}\right)^{5 / 2} \frac{P_{2}}{P_{1}}
$$

First guess for $\mathrm{M}_{1}$, i.e., $\mathrm{M}_{1,1}$ is

$$
M_{1,1}=0.8813\left(\frac{P_{1_{t}}}{P_{1}}\right)_{\text {measured }}^{1 / 2}
$$

Substitute first guess for $\mathrm{M}_{1}=\mathrm{M}_{1,1}$ into

$$
\frac{P_{2_{t}}}{P_{1}}=\frac{166.926 M_{1, n}^{7}}{\left(7 M_{1, n}^{2}-1\right)^{5 / 2}}
$$

Check to see if

$$
\frac{\left|\left(\frac{P_{2}}{P_{1}}\right)_{\text {measured }}-\left(\frac{P_{2}}{P_{1}}\right)_{n}\right|}{\left(\frac{P_{2}}{P_{1}}\right)_{\text {measured }}}>\text { or }<0.0001
$$


If

$$
\frac{\left|\left(\frac{P_{2}}{P_{1}}\right)_{\text {measured }}-\left(\frac{P_{2}}{P_{1}}\right)_{n}\right|}{\left(\frac{P_{2}}{P_{1}}\right)_{\text {measured }}}<0.0001
$$

Put $\mathrm{M}_{1, \mathrm{n}}=\mathrm{M}_{1}$ and proceed with the calculation of

$$
\frac{P_{1}}{P_{1}}=\left(\frac{M_{1}^{2}+5}{5}\right)^{7 / 2}
$$

which is step 3 in the data reduction procedure.

If

$$
\frac{\left|\left(\frac{P_{2}}{P_{1}}\right)_{\text {measured }}-\left(\frac{P_{2}}{P_{1}}\right)\right|}{\left(\frac{P_{2}}{P_{1}}\right)_{\text {measured }}}>0.0001
$$

substitute $\left(\frac{P_{2_{T}}}{p_{1}}\right)_{\text {measured }}$ from $\mathrm{M}_{1, \mathrm{n}}$ into

$$
M_{1, n+1}=M_{1, n}\left\{1+\frac{\left(\frac{P_{2}}{P_{1}}\right)_{\text {measured }}-\left(\frac{P_{2}}{P_{1}}\right)_{n}}{\left(\frac{P_{2}}{P_{1}}\right)_{\text {measured }}}\right\}
$$

to get $M_{1, n+1}$ which, in turn, is substituted $n$ equation (1a) and the process is repeated.

Symbols

$\mathrm{M}_{1} \quad$ Mach number behind shock from wedge leading edge. 


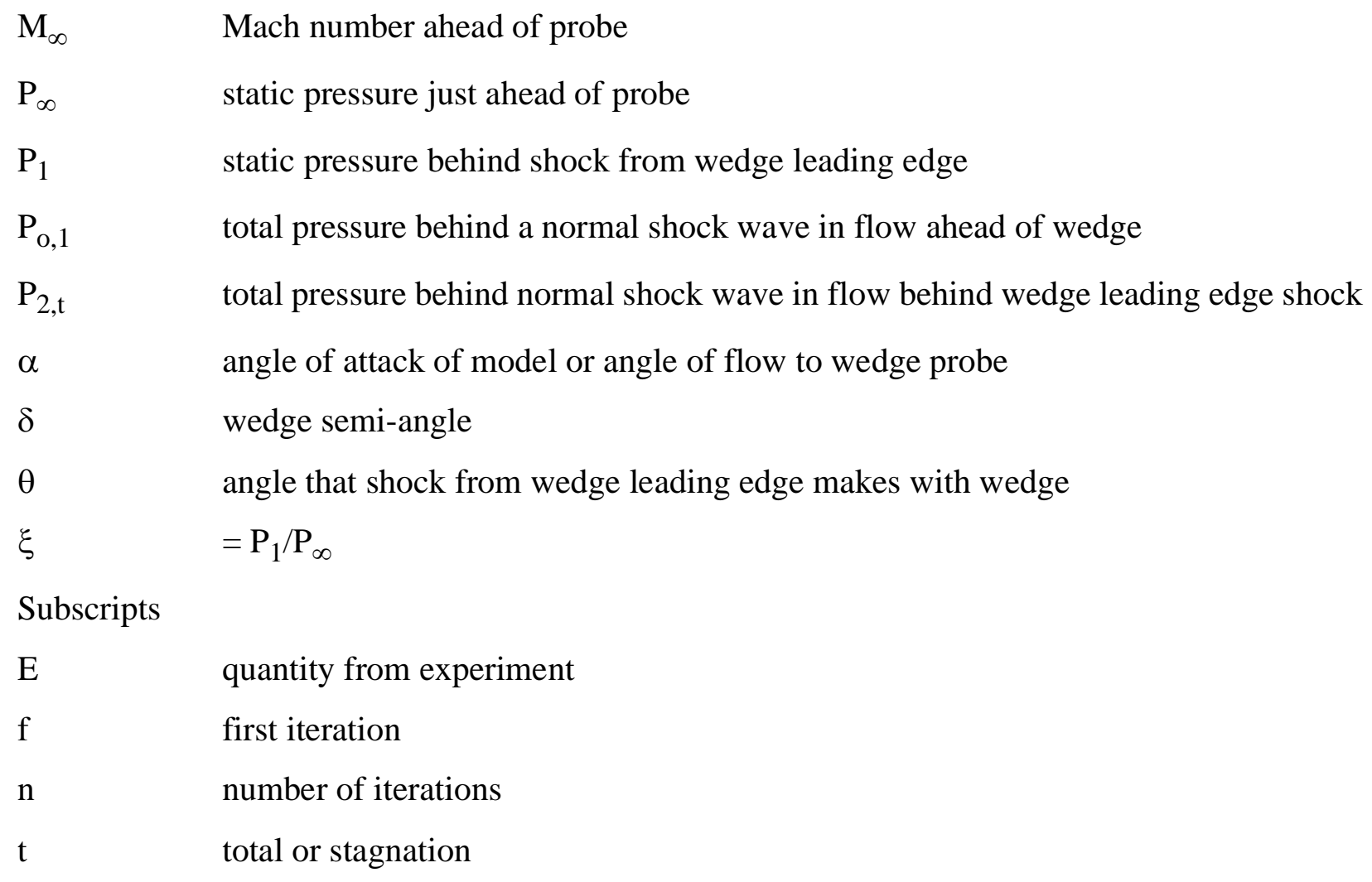

\section{Appendix B}

\section{Procedure for Calculating the Free-Stream Variables from the Measured} Quantities for the Conical Probe

The measured quantities are $\mathrm{H}_{\mathrm{T}}, \mathrm{P}_{\mathrm{c}, 1 \mathrm{o}}, \mathrm{P}_{\mathrm{c}, \mathrm{u}}, \mathrm{P}_{\mathrm{c}, l}, \mathrm{P}_{\mathrm{c}, \mathrm{r}}, \mathrm{T}_{\text {meas }}$ and $\mathrm{P}_{\mathrm{i}}$. The basic equation for Mach number and flow-angle equations are:

$$
\begin{gathered}
M_{\infty_{n}}=0.2637+0.5397\left(\frac{H_{T}}{P_{c_{a v}}}\right)-0.0158\left(\frac{H_{T}}{P_{c_{a v}}}\right)^{2}+\frac{i_{n}}{1000}\left[0.673-0.657\left(\frac{H_{T}}{P_{c, a v}}\right)+0.127\left(\frac{H_{T}}{P_{c, a v}}\right)^{2}\right] \\
i_{n+1}^{2}=\alpha_{n+1}^{2}+\beta_{n+1}^{2} \\
\alpha_{n+1}=\frac{P_{c_{l o}}-P_{c_{u}}}{H_{T}}\left(59.5-\frac{14.7}{M_{n}}+\frac{39.4}{M_{n}^{2}}\right)
\end{gathered}
$$




$$
\begin{aligned}
& \beta_{n+1}= \frac{P_{c_{l}}-P_{c_{r}}}{H_{T}}\left(59.5-\frac{14.7}{M_{n}}+\frac{39.4}{M_{n}^{2}}\right) \\
& P_{c_{a v}}= \frac{P_{c_{u}}+P_{c_{l}}+P_{c_{l o}}+P_{c_{r}}}{4}-\mathrm{P}_{\mathrm{P}, \mathrm{c}, \mathrm{l}, l} \\
& 4
\end{aligned}
$$

Calculation procedure:

With the measured quantities $\mathrm{H}_{\mathrm{T}}$ and $\mathrm{P}_{\mathrm{c}, \mathrm{av}}$, see equation (5), and with $\mathrm{i}_{\mathrm{n}}$-set equal to zero, i.e., $\mathrm{i}_{\mathrm{n}}=\mathrm{i}_{1}=0$, calculate

$$
M_{\infty_{n}}=M_{\infty, 1}
$$

from equation (1).

Then with $M_{\infty_{1}}$ and measured pressures calculate $\alpha_{n+1}=\alpha_{2}$ and $\beta_{n+1}=\beta_{2}$ and

$$
i_{n+1}^{2}=i_{2}^{2}=\alpha_{2}^{2}+\beta^{2}
$$

from equations $(3,(4)$ and (2).

Then increase index $\mathrm{n}$ to 2 , i.e. $\mathrm{n}=2$, in, equation (1) and calculate $M_{\infty_{2}}$ using $\mathrm{i}_{2}$.

With $M_{\infty_{2}}$ and $M_{\infty_{1}}$, check to see $M_{\infty_{n}}-M_{\infty_{n-1}}=M_{2}-M_{1} \leq 0.002$

If not, continue calculation with $M_{\infty_{2}}$ to obtain $\alpha_{3}, \beta_{3}$ and $i_{3}$ from equations (2), (3) and (4), and with index in equation (1) increased to 3 , i.e, $\mathrm{n}=3$ and calculate $M_{\infty_{3}}$. Then check $M_{\infty_{n}}-M_{\infty_{n-1}}=M_{\infty_{3}}-M_{\infty_{2}} \leq 0.002$, and so on until test is satisfied.

Once $M_{\infty}$ is determined, calculate

$$
P_{t_{\infty}}=H_{T}\left[\frac{7 M_{\infty}^{2}-1}{6}\right]^{5 / 2}\left[\frac{6 M_{\infty}^{2}}{M_{\infty}^{2}+5}\right]^{-7 / 2}
$$


and with $P_{t_{\infty}}$ from equation (6) calculate

$$
P_{\infty}=P_{t_{\infty}}\left(1+0.2 M_{\infty}^{2}\right)^{-7 / 2}
$$

Also with measured $\mathrm{T}_{\text {meas }}, \mathrm{H}_{\mathrm{T}}$ and $\mathrm{P}_{\mathrm{i}}$ calculate

$$
T_{2}=T_{\text {meas }}\left(\frac{H_{T}}{P_{i}}\right)^{2 / 7}
$$

With

$$
T_{t, \infty}=T_{2}
$$

and $P_{t, \infty}$ from equation (6) the total free-stream density can be determined by)

$$
\rho_{t, \infty}=\frac{P_{t, \infty}}{R T_{t, \infty}}
$$

The free-stream temperature is determined by

$$
T_{\infty}=T_{t, \infty}\left(1+0.2 M_{\infty}^{2}\right)^{-1}
$$

using $T_{t, \infty}$ from equation (9).

And with $T_{\infty}$ the free-stream static speed-of-sound can be determined by

$$
a_{\infty}=\sqrt{1.4 R T_{\infty}}
$$

With this quantity and the converged valued for $M_{\infty}$, free-stream velocity is obtained.

$$
V_{\infty}=M_{\infty} a_{\infty}
$$

Finally, if acceleration of interest, it can be determined using the time-varying velocity from by equation (13), i.e.,

$$
\text { Acceleration }=\frac{\Delta V_{\infty}(t)}{\Delta t}
$$

The rate of change of Mach number with Time can be calculated in a similar fashion using the Mach number calculated by equation (1). 


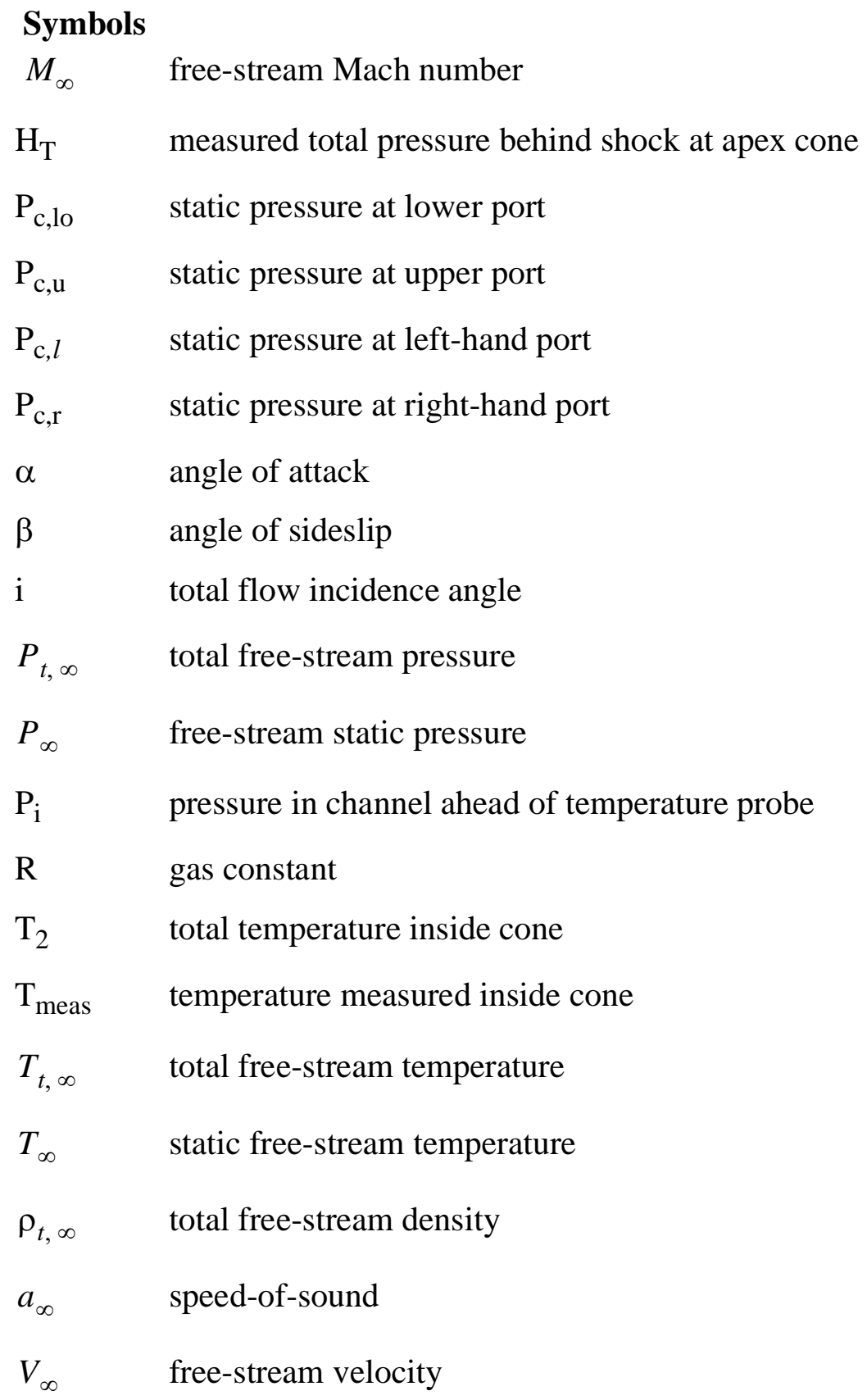

Note: Flight data for conical and wedge probes will be acquired after the first of the year (2011) and added to the final manuscript 